\title{
Viability of Seasonal Natural Gas Storage in the Saudi Energy System
}

\section{Walid Matar and Rami Shabaneh}




\section{About KAPSARC}

The King Abdullah Petroleum Studies and Research Center (KAPSARC) is a non-profit global institution dedicated to independent research into energy economics, policy, technology and the environment across all types of energy. KAPSARC's mandate is to advance the understanding of energy challenges and opportunities facing the world today and tomorrow, through unbiased, independent, and high-caliber research for the benefit of society. KAPSARC is located in Riyadh, Saudi Arabia.

This publication is also available in Arabic.

\section{Legal Notice}

(c) Copyright 2019 King Abdullah Petroleum Studies and Research Center ("KAPSARC"). This Document (and any information, data or materials contained therein) (the "Document") shall not be used without the proper attribution to KAPSARC. The Document shall not be reproduced, in whole or in part, without the written permission of KAPSARC. KAPSARC makes no warranty, representation or undertaking whether expressed or implied, nor does it assume any legal liability, whether direct or indirect, or responsibility for the accuracy, completeness, or usefulness of any information that is contained in the Document. Nothing in the Document constitutes or shall be implied to constitute advice, recommendation or option. The views and opinions expressed in this publication are those of the authors and do not necessarily reflect the official views or position of KAPSARC. 


\section{Key Points}

audi Arabia expects to double its natural gas production within the next decade. This increased domestic supply is expected to meet the demand for gas from Saudi Arabia's industrial development and, most importantly, to displace liquid fuels in its electricity sector. Given the strong seasonal variability of the latter, underground gas storage (UGS) can help ensure the availability of gas to meet peak power load.

In this vein, we assess the geologic and economic viability of UGS in Saudi Arabia under different scenarios: with and without LNG imports allowed, and under low and high domestic gas production. Depleted oil fields or aquifers are best suited for gas storage in the Kingdom. Using a model of the country's energy system, we show that in the case of high gas production, storage capacity would be built to bypass the transport limit for gas for use in electricity generation in the summer. In the low production case, gas storage would facilitate optimal gas use among sectors throughout the year. The net present gain - defined as the discounted sum of the annual differences in benefits and costs - is used to determine the economic viability of gas storage.

Overall, gas storage in the high gas supply case would deliver a positive gain of nearly $\$ 900$ million throughout the energy system.

With low gas supply, the cost of gas storage for the upstream sector would exceed the benefit of lower costs realized in other sectors.

The results indicate that gas storage installations are favorable in the case of high domestic gas production. If production turns out to be lower, liquefied natural gas (LNG) imports would be more sensible. 


\section{Summary}

uel prices in Saudi Arabia have historically been below international market values.

The Saudi government plans to raise them in the coming years to better reflect their cost of production or their value on the international markets (SV2030 2017). Matar and Anwer (2017) showed, through the emergence of renewable power generation technologies, that raising the domestic prices of fuel in Saudi Arabia would result in an increased seasonal cyclicality of natural gas use, beyond what could be caused by the seasonal variations in electric power use alone.

The transportation of gas to power plants would be capped in the high-power-load summer months. Other industrial uses for natural gas would also constrain domestic gas availability for power generation year-round. The cap would be reached in the summer but not during low-load periods such as the winter. The scarcity and daily transport limit of domestic natural gas would therefore require the power utilities to look for the next least-cost method to satisfy the incremental electricity demand. As fuel prices rise over the years, renewable generation technologies become economically more attractive. Renewable technologies are characterized by low marginal costs once installed, which would put them first in the merit order in the winter months, beating some natural gas plants. This would further widen the seasonal variations in gas use.

Relevant questions that arise include, how does one optimize the utilization of domestic natural gas in the Saudi energy system? Will the industrial use of natural gas in the winter compensate for the seasonal swings in the power sector? These questions are especially pertinent to the local gas supplier, Saudi Aramco. We look at two possible mitigation options that are combined in the KAPSARC Energy Model (KEM), calibrated for Saudi Arabia:
The ability to use the spare pipeline capacity in the winter to transfer natural gas to storage facilities; Saudi Arabia does not presently store natural gas. The stored natural gas would then be used in other seasonal periods, or whenever needed. This may offer power plants more natural gas than they would have received in the summer because of the cap on gas transport. Since natural gas storage would provide more gas during the summer, it may also reduce the number of renewable technologies deployed.

The higher prevalence of variable renewable generation to meet summer demand causes thermal generators to operate at lower capacity factors year-round. That would call upon the system operator to issue capacity payments to encourage the operation of and investment in thermal plants (Baldick et al. 2005). If natural gas storage could help meet summer demand, the lower deployment of renewable generation would mitigate this issue for thermal plants.

Unused natural gas could be diverted to industries other than the power utilities in the winter. There is high demand from other industries for natural gas, and this will be further emphasized by increased domestic oil prices. This paper focuses on the fertilizer and cement industries, as they are the second biggest natural gas consumers after the power utilities.

Three types of underground gas storage (UGS) are used in practice: depleted oil and gas fields, aquifers, and salt caverns. The former two types of UGS facilities are chosen in this analysis due to the geological make-up of the Arabian Peninsula. The net present gain - defined as the discounted sum of the annual differences in benefits and costs relative to a reference case - is used to determine the economic viability of gas storage. Overall, the 
energy system would experience a positive gain of $\$ 900$ million with gas storage in the high gas supply case. With low gas supply, the cost of gas storage for the upstream sector would exceed the benefit of lower costs realized by other sectors. Lower costs are derived from lower gas prices, which arise from allowing consumers that could not use gas in the summer to do so. Ultimately, if domestic gas production is high, the results indicate that gas storage facilities are the best option for bypassing the transport limit to power plants. If gas production turns out to be low and the transport limit is not binding, liquefied natural gas (LNG) imports would start to be a more sensible option. 


\section{Natural Gas Infrastructure in Saudi Arabia}

M ost of the producing oil and gas wells in Saudi Arabia are located in the eastern part of the country, including the offshore fields in the Arabian Gulf. Saudi Aramco's Master Gas System (MGS) enables gas to be transported from the Arabian Gulf to the central, western and southern areas of the Kingdom. However, pipeline capacity constraints on the MGS and high demand in the east have restricted gas going westward; historically, the price of gas has been too low to warrant further investment. Recent announcements by Saudi Aramco and the Ministry of Energy, Industry, and Mineral Resources (MEIM) call for the doubling of domestic natural gas production between 2017 and 2027 (Saudi Gazette 2017). This indicates the price of gas will rise in the future to cover higher marginal-cost production. As gas production increases, the associated infrastructure is expected to expand to accommodate new gas supplies. Saudi Aramco has started expanding the MGS and plans to increase its capacity further, including the 1,000 kilometer $(\mathrm{km})$ East-West pipeline (Platts 2017).

We hypothesize that Saudi Arabia's natural gas storage infrastructure will provide power plants with natural gas during peak power load periods, i.e., in the summer months. So far, there is no record of seasonal storage or LNG infrastructure in Saudi Arabia. In fact, the latest statistics show that in the Middle East, only Iran and the United Arab Emirates (UAE) have UGS. Both countries have a combined total of 9.9 billion cubic meters (bcm), or $2.3 \%$ of global UGS capacity (CEDIGAZ 2017). 


\section{Natural Gas Storage and Industrial Use: Global Experiences and Seasonality}

\section{Seasonal storage of natural gas}

Natural gas storage is an integral part of the natural gas supply chain. In countries that experience a wide range of seasonal variation in gas demand, storage may strengthen the security of supply. Storage operators usually buy and inject gas into storage units during the off-peak season, and withdraw it to sell during periods of high demand, creating arbitrage between seasonal price differences (Hinchey 2017). There is no opportunity for arbitrage in Saudi Arabia as it does not have a natural gas market; there is only one gas producer and distributor, and the fuel has a flat year-round price.

Three UGS options are primarily used in practice: depleted oil and gas wells, aquifers, and salt cavern formations. Natural gas storage options are differentiated by their base gas and working gas capacities, the injection rate of gas into and out of the facility, and cycling abilities. Base gas refers to the natural gas quantity that has to be in the facility to maintain enough pressure for extraction. Working gas is the amount of natural gas that can be extracted. The injection rate of gas into the facility is highest when there is a small quantity of gas stored, and it decreases as the storage facility fills up. This reverses for withdrawal from the facility, as static pressure rises with more gas in storage. Cycling refers to how many times per year gas can be deposited and withdrawn. So far in the Middle East, only Iran and the UAE are reported to operate UGS, and these facilities are all depleted oil and gas fields (CEDIGAZ 2017). Because all three UGS options are naturally occurring, their availability is restricted to the geological and geographical traits of the local area (Hinchey 2017).
The United States (U.S.) has 392 UGS facilities in operation, out of a global total of 672 facilities, with a capacity of about $134 \mathrm{bcm}$. Thompson et al. (2009) highlight UGS in the U.S. was meant to balance the supply of gas between the high-demand winter months and the lower-demand summer months. However, the difference between seasonal demand has dampened in recent years, as gas-fired generation has risen to meet peak summer loads. Figure 1 illustrates this shift, showing the monthly quantities of stored gas in the U.S.; large volumes are injected into storage during the summer months and withdrawn in the winter.

Other countries with significant UGS capacity include Russia, Ukraine, Canada, Germany, Italy, and the Netherlands. These countries all consume more natural gas during the winter months to meet heating demand. Given this demand profile, these countries typically store large amounts of gas during the summer months and show net withdrawals in the winter. However, in Saudi Arabia, the difference in seasonal gas demand is reversed.

The literature shows that Saudi Arabia's topography contains all three types of UGS formations. Husseini and Husseini (1990) show, along with Folle (2006), that northeast Saudi Arabia contains parts of the Gotnia salt basin that can be used to construct salt caverns. There are many aquifers in the Western region, especially in Tabuk (Jaju et al. 2016). Given the hydrocarbon-rich zones in the eastern and central parts of the country, many depleted oil and gas fields in these areas can be used for seasonal storage. The Saudi Geological Survey has produced hydrogeological maps identifying aquifer characteristics in the Arabian Shield (the geological formation in the Western region), and it continues to survey the area (Saudi Geological 
Figure 1. Weekly gas storage estimates in the U.S. from 2013 to 2017.

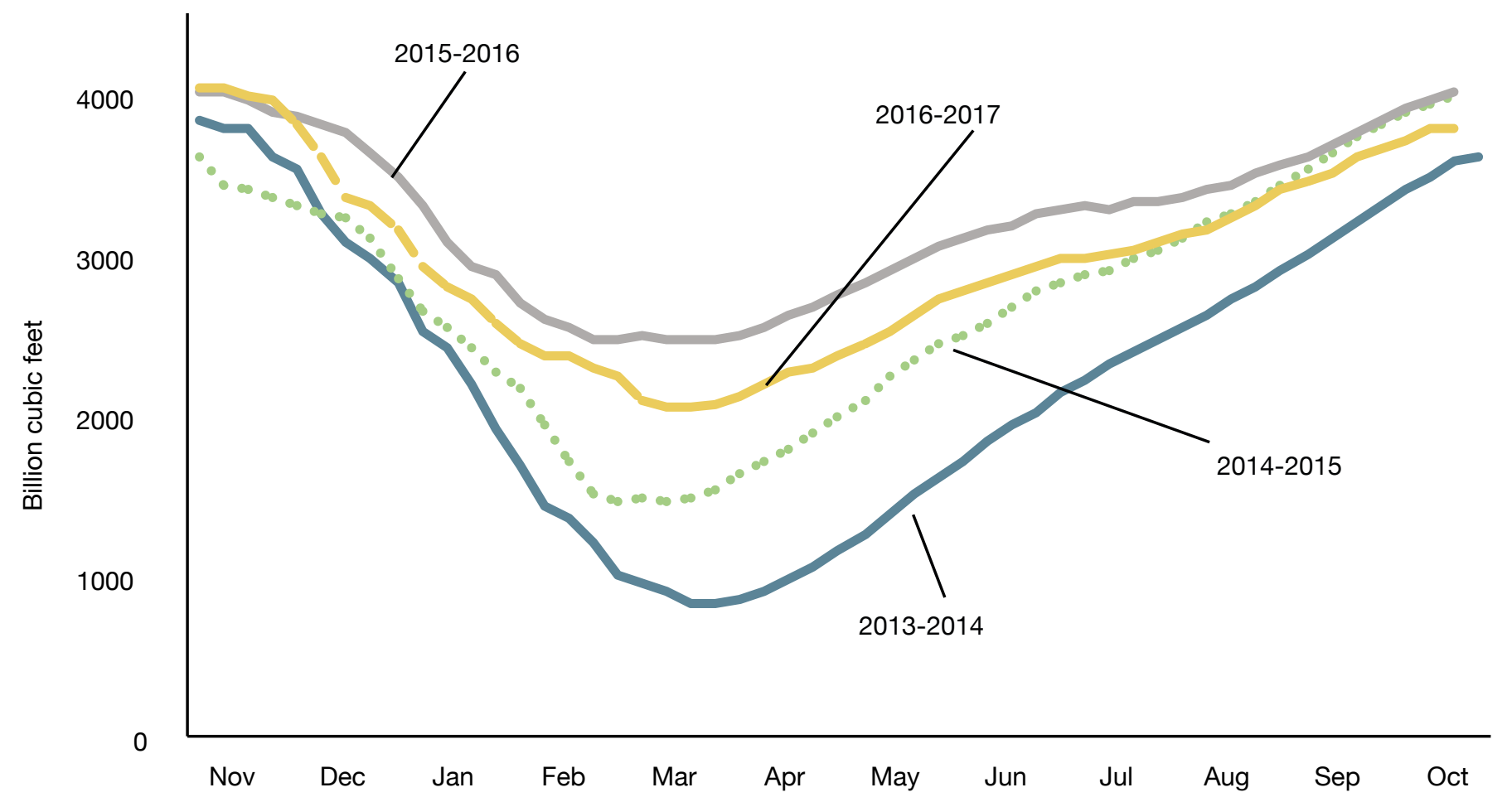

Source: Energy Information Administration (IEA).

Survey 2018). There are also traces of salt deposits in and around Jizan in the southwest as well as in the coastal plains south and north of Jeddah (Folle 2006). Oil and gas activity in the Red Sea and the Midyan Basin, in the northwest of the country, might leave behind depleted wells that could be utilized for storage.

Technically, Saudi Arabia can install UGS along the MGS in the eastern, central, or western areas, with feeder lines giving easy access to the gas. However, a storage facility in the Western region would guarantee the availability of gas, bypassing any potential congestion issues along the MGS during the summer months. Aquifer storage facilities could be the best option for storage in the Western region, given its proximity to demand centers and its geology.

\section{Seasonal fuel use by industry}

Seasonal data for industrial operations in Saudi Arabia is not publicly available. Wiggins and Etienne (2017) point to the fact that there are only a handful of studies on the demand structure of natural gas in the U.S. Their review of these papers does not address the seasonality of industrial gas use.

Seasonal natural gas use in the U.S. is dominated by the demand from commercial and residential customers for heating during the winter. U.S. industrial producers typically consume more natural gas in winter than in summer and have more variable demand than that from power generation and residential heating. As Figure 2 shows, the U.S. industrial peak declined from June 2017 to January 2018 by $21 \%$ (EIA 2018a). The Energy Information 
Administration (EIA) (2018b) shows similar seasonal patterns for the industrial use of natural gas for non-combustion purposes. It is unclear whether industry substitutes gas with other feedstock for producing goods during summer, or if industrial output itself is seasonal.

The available gas in winter in Saudi Arabia could be supplied to industry. Since many of the fertilizers produced in Saudi Arabia are exported, the seasonal demand for them may vary depending on the export destinations. It will be interesting to see if the model's results support this assertion. We make this hypothesis because natural gas will primarily be produced in the Eastern Province, even if a portion of future non-associated gas will come from the Red Sea. Fertilizer plants are also mostly located in the Eastern Province and are already connected to the MGS. It may be more valuable to divert gas to nearby fertilizer plants in the winter, and store fertilizers for their high-demand season, rather than store gas for power generation. We will explore this trade-off between seasonal storage for power generation and seasonal industrial use. Previous versions of KEM represented the operation of the fertilizer industry annually, whereas this study represents it by seasons, to allow for seasonal flexibility.

Figure 2. Monthly natural gas use in the U.S. (2010-2017).

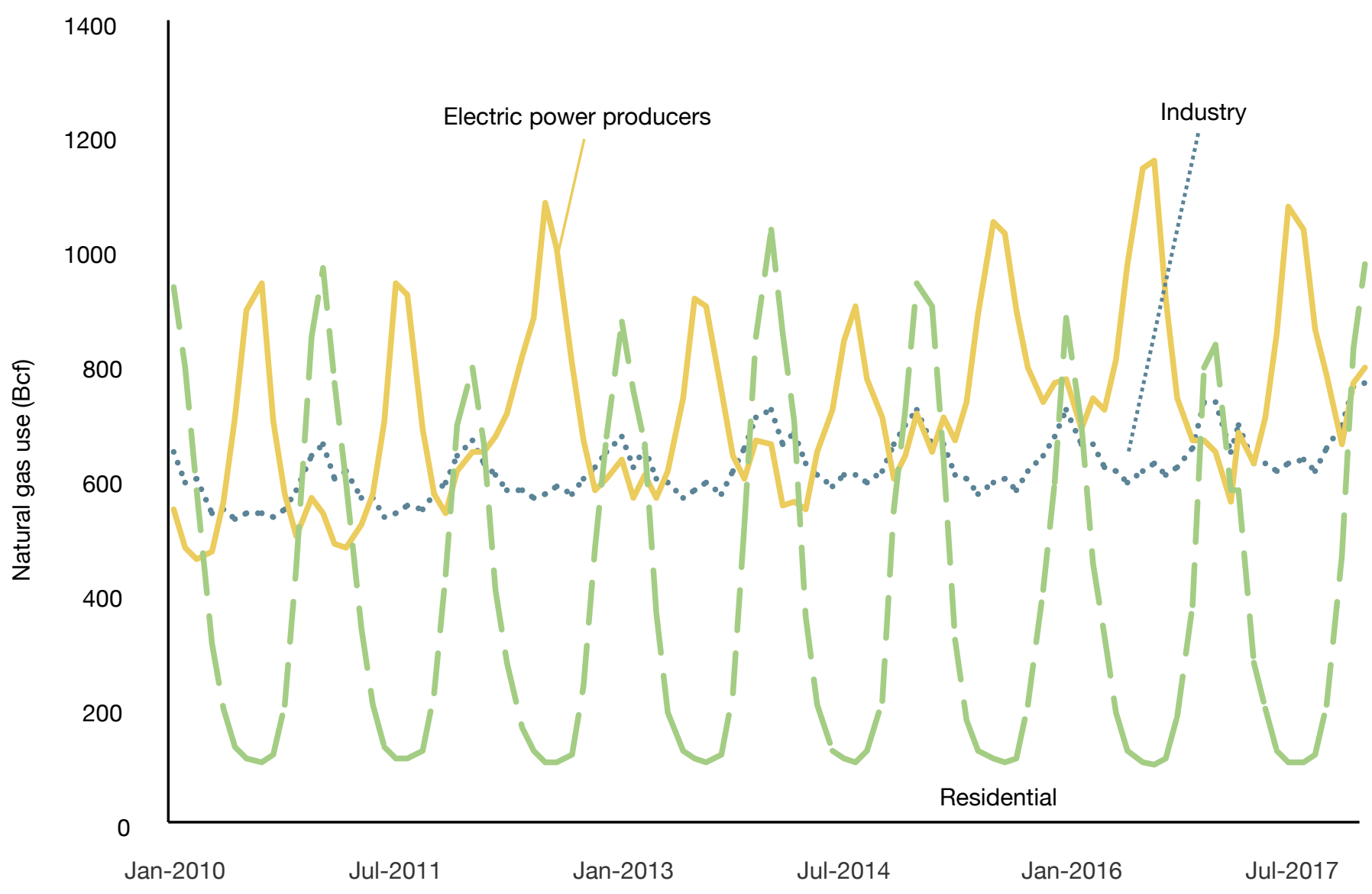

Source: EIA (2018a). 


\section{Analysis Approach}

\section{Modeling component}

KEM is a tool developed by KAPSARC (2016) to help assess the consequences of alternative policies that affect energy production and use within Saudi Arabia. It allows the analysis of all seasonal gas use options simultaneously, while also considering the operation of the entire energy system. The model is formulated as a mixed complementarity problem that allows easy consideration of goods' prices in each consuming sector that deviate from their marginal costs of production (Murphy et al. 2016). It divides the country into four regions based on the operating areas of the Saudi Electricity Company (SEC), to account for varying climates and socio-economic conditions. The sectors represented in the model and the flows of energy goods between them are illustrated in Figure 3. For example, the petrochemicals industry can use a refined oil product such as naphtha, but it may also supply refining plants with methyl tert-butyl ether (MTBE), which they would blend with other gasoline components.

For electricity generation, the model considers the operation of power plants in the summer, winter, and an intermediate seasonal period, and two day types for weekdays and weekends/holidays. The resulting 24-hour daily profiles are further broken up into eight non-uniform load segments. Hence, six daily curves represent load demands for each region. This allows for a manageable model that can be solved within a reasonable timeframe.

We include additional features in KEM to help address the subject at hand. We now allow for seasonal operation in the upstream oil and natural

Figure 3. The version of the KAPSARC Energy Model used in this analysis.

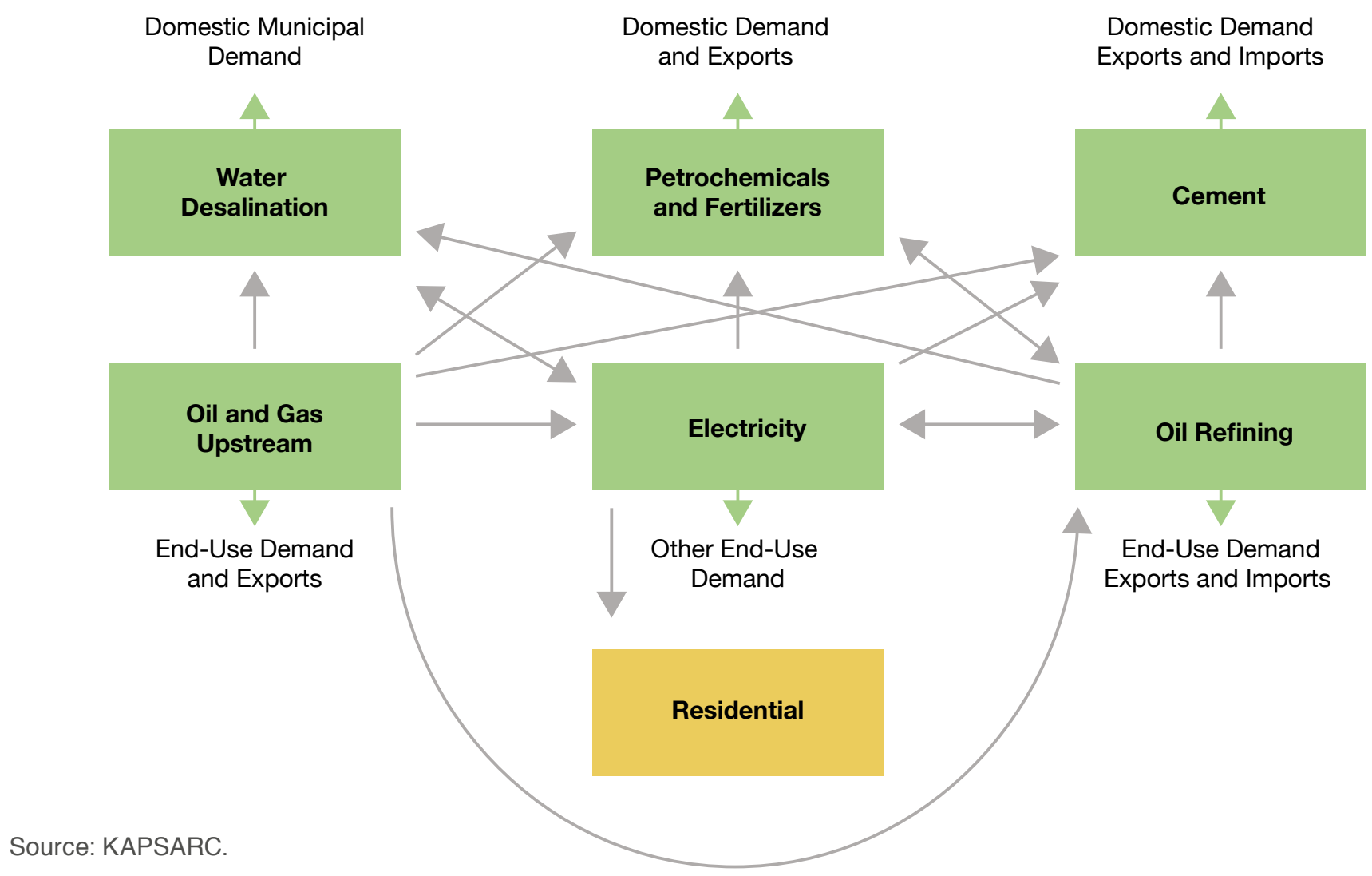


gas sector. We also add seasonal natural gas storage features in the model, as described in Appendix A. As our implementation indicates, our main interest when it comes to storage is to support industrial and power companies' seasonal use of natural gas. We do not necessarily aim to facilitate price arbitrage, as Saudi Arabia does not have a market and the price of natural gas is fixed by the government. Gas storage in KEM is represented by either aquifers in the central, western, and southern areas, or depleted oil and gas reservoirs in the east of the country. The lack of salt formations in the former three regions prohibits the use of salt caverns, and the east already contains depleted reservoir options. Injecting natural gas into storage requires some energy for the compressor, which is represented by a loss of gas during the storage process. Moreover, we maintain a certain percentage of the stored natural gas as base (cushion) gas.

Second, the petrochemicals, fertilizer, and cement industries have been expanded to operate seasonally. These industries' operation, and therefore their natural gas and feedstock use, is seasonal. The annual regional demand for each industry's goods is distributed across seasons by taking a weighted average with respect to time. Matar and Elshurafa (2017) describe the ability of the cement sector sub-model in KEM to store cement on an annual basis. Seasonal cement storage is now represented in a similar way to that of natural gas, but without the base gas requirement and the need for a compressor when storing the cement. So in theory, cement companies can opt to use fuel in one season, store the finished product at an operational cost, and deliver it to customers in another season.

These three industries add to the seasonality of the electricity generation and water desalination sectors. To manage the number of variables in
KEM, we opted for the annual operation of the oil refining sector. Some additional features added to this version of KEM that have not been previously documented include the following:

The ability to import LNG in the upstream oil and gas sector.

LNG imports are represented as imports in all regions except for the central operating area, as the central region is landlocked.

Floating storage and regasification units (FSRUs) can be installed along both coasts. LNG can be transported through the Suez Canal from the Mediterranean Sea to serve the western or southern areas.

As a modeling assumption, potential imports are only used as fuel for power generation.

Moreover, previous versions of KEM imposed limits of natural gas use for the power sector for certain regions within Saudi Arabia. We now impose these caps at the national level, and the model distributes the regional allocation of gas optimally. This revision allows for any future expansion of the MGS that would alter the regional distribution of gas use.

Related to the previous point, past versions of KEM have applied natural gas use limits annually. We have added a constraint in the electricity sector sub-model to account for the average daily use of natural gas by electricity generators, to adhere to the daily transport capacity; this is described in Appendix A.

Neglecting the daily limit when using KEM in previous analyses meant that the model violated the gas transport capacity in the high-load summer months. This would have underestimated how much alternative generation technology is built, because 
in real-life, the transport capacity would be binding in the summer, and the power system would have to look for alternative means to meet demand. Although a finer discretization of the year is desired, we cannot expand the model further as it is teetering on the edge of tractability. We could only apply this change for the electric power sector because we have daily transport capacity projections from MEIM. We do not have similar data for other sectors.

Pumped seawater storage hydroelectricity (PSSH) has also been added as a prospective power technology. PSSH may be used to contribute to the operating reserves for backing up intermittent renewable generation. Appendix $B$ describes its implementation in KEM.

\section{Using KEM until 2030}

The initial condition of the model is calibrated to 2015. The next sub-section and Appendices A, B, and $C$ detail much of the data input from 2015 to 2030. The model is operated until 2030. However, the multi-period approach entails the sectors making their operational and investment decisions looking ahead four years on a rolling basis.

The sectors consider the first four years for planning in 2015. In the second year, they consider the four years after that, dropping the first of the first four years and adding another year at the end. The model continues this process until the sectors eventually reach a period of time less than four years from 2030, at which point the number of years the sectors can foresee is shortened. In the last year of the analysis, the model is run in a steady-state framework, assuming that last year is infinitely recurring, in which investment costs are fully annualized and thereby made comparable to the operational costs of the technologies. This recursive dynamic method would factor in the uncertainty decision-makers within the industry face about the future.
For example, domestic natural gas prices doubled abruptly in 2016, something the consuming sectors could not have anticipated. The model does not take into consideration any anticipation of the 2016 price reform plan in 2015 . The model correctly represents the sectors' planning in 2015. Running the model with the sectors able to anticipate the price reform plan of 2016 would change their decisions in 2015.

\section{Assessment of policy options}

Two sets of policy scenarios are devised to assess the viability of seasonal storage of domestically sourced natural gas. Each set is defined by a high or low domestic sales gas supply projection, as shown in Figure 4. Saudi Aramco (2017) states that around 3 quadrillion British thermal units (Btu) (7.9 billion cubic feet per day [Bcf/d]) of Saudi natural sales gas was produced in 2015, and 3.15 quadrillion BTU (8.3 Bcf/d) in 2016. In the high gas supply case, we estimate that the domestic sales gas supply will linearly reach 2.5 times the 2015 value by 2030 , whereas in the low supply case, a multiplier value of 1.5 times is used. Platts (2017) reported that Saudi Arabia plans to expand the MGS to achieve a capacity of $12.5 \mathrm{bcf} / \mathrm{d}$ of sales gas by 2020. That expansion plan would be consistent with our high gas supply projection case if the daily transport limit is multiplied by 365 days per year.

The average cost of extraction for the upstream sector is higher in the high supply case because any further increases in gas supply are going to be predominantly non-associated. Following Alyousef and Stevens (2011), we estimate the cost of marginal non-associated gas production is constant at \$4 per million British thermal units (MMBtu), in real terms. The marginal cost of associated gas is taken as zero since it is a by-product of oil production. 
Figure 4. Projections for domestically sourced sales natural gas supply.

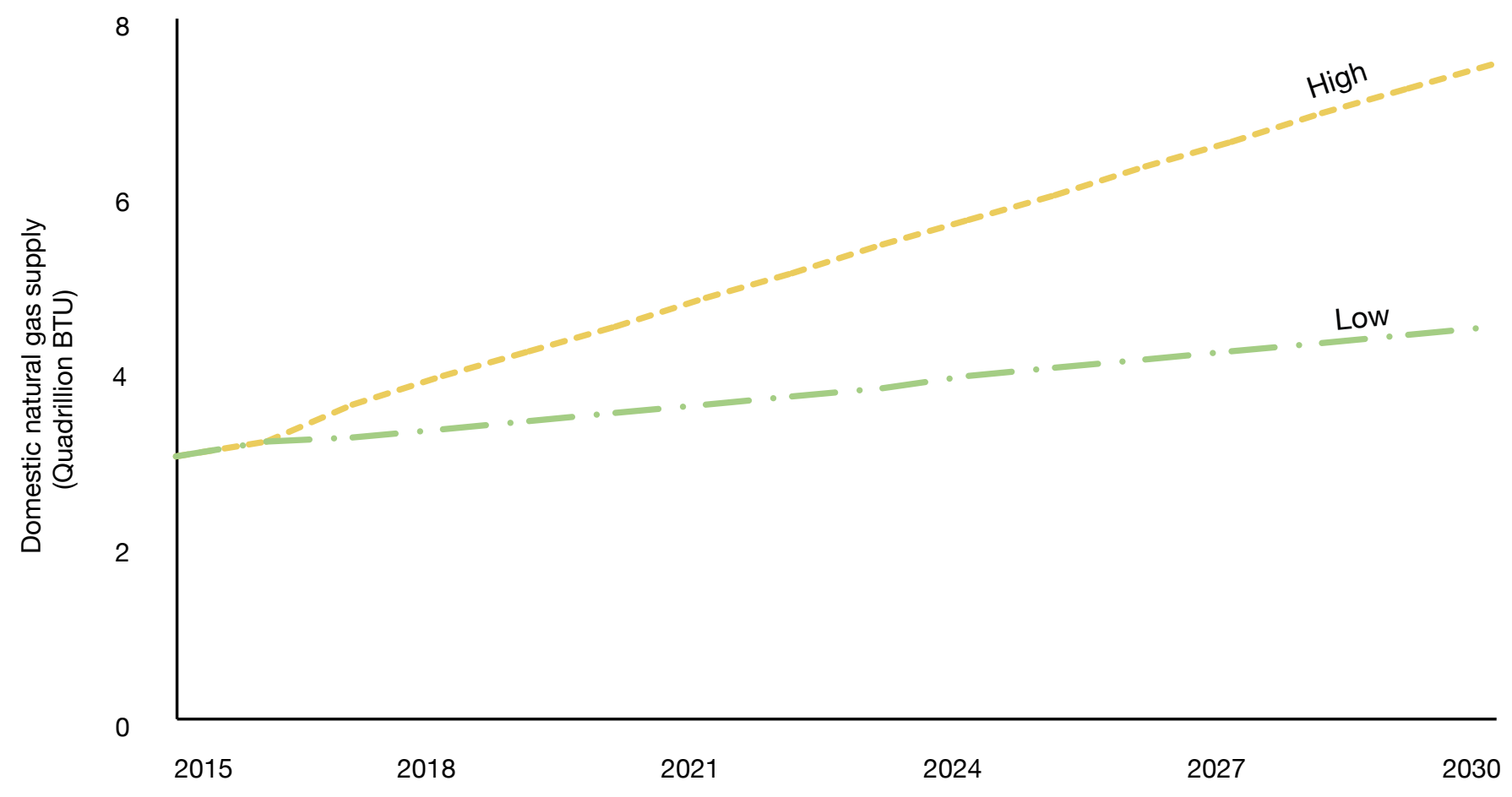

Sources: KAPSARC analysis; Saudi Aramco (2017).

We examine the four policy options in both sets, shown in Table 1. These policy options combine two policy levers: whether power utilities are allowed to import LNG, and whether the oil and gas upstream sector is allowed to invest in gas storage facilities. For each set, the reference case to which all three other cases are compared has no natural gas storage and no LNG imports.

Table 1. Policy scenarios considered in the high and low domestic natural gas supply cases.

\begin{tabular}{l|c|c} 
& $\begin{array}{c}\text { Allowing import of LNG for power } \\
\text { plants }\end{array}$ & $\begin{array}{c}\text { Option to invest in storage facilities } \\
\text { for domestic natural gas }\end{array}$ \\
\hline LNG and storage & $\checkmark$ & $\checkmark$ \\
\hline No LNG with storage & - & $\checkmark$ \\
\hline LNG without storage & $\checkmark$ & - \\
\hline No LNG or storage & - & -
\end{tabular}

Source: Ministry of Environment, Forests and Climate Change, India. 
Both sets consider fuel price increases that are consistent with the planned price reforms. Industrial fuel prices were last raised in 2016. As shown in Figure 5, we assume that fuel prices will be gradually raised again, starting in 2019 . To be consistent with Saudi Vision 2030 (SV2030 2017), we also assume that the prices of crude oil and refined petroleum products will reach global benchmarks by 2023. The prices of propane and naphtha offered to petrochemical producers are tied to the cost and freight price of naphtha in Japan; this is the continuation of existing policy (ICIS 2013).

The prices of domestic natural gas and ethane are specified at their current, government-set, levels. In 2015, the price of methane and ethane was $\$ 0.75 / \mathrm{MMBtu}$. Their prices were raised in 2016 to $\$ 1.25 / \mathrm{MMBtu}$ and $\$ 1.75 / \mathrm{MMBtu}$, respectively. Their corresponding market-clearing prices from
2018 onward are used in this analysis. Under the competitive equilibrium assumption, the market-clearing condition is determined by the model as the price at which the supply and demand curves of gas intersect. The results and discussion section elaborates on this. We expect the two price series to increase as the gas supply is reduced. That condition means the scenarios do not require the enforcement of government-sanctioned sectoral quotas, or rations, as the model will allocate the available resources optimally to each sector.

We use quarterly LNG prices, as we expect that LNG would be primarily imported in the summer months to meet the high power loads. If this turns out to be true, then we want the model to consider lower LNG prices in the summer. Given that global natural gas demand peaks in the winter months for heating, LNG prices would be lower outside this

Figure 5. Prices of oil products and LNG offered to the power and water utilities and industrial sectors in KEM.

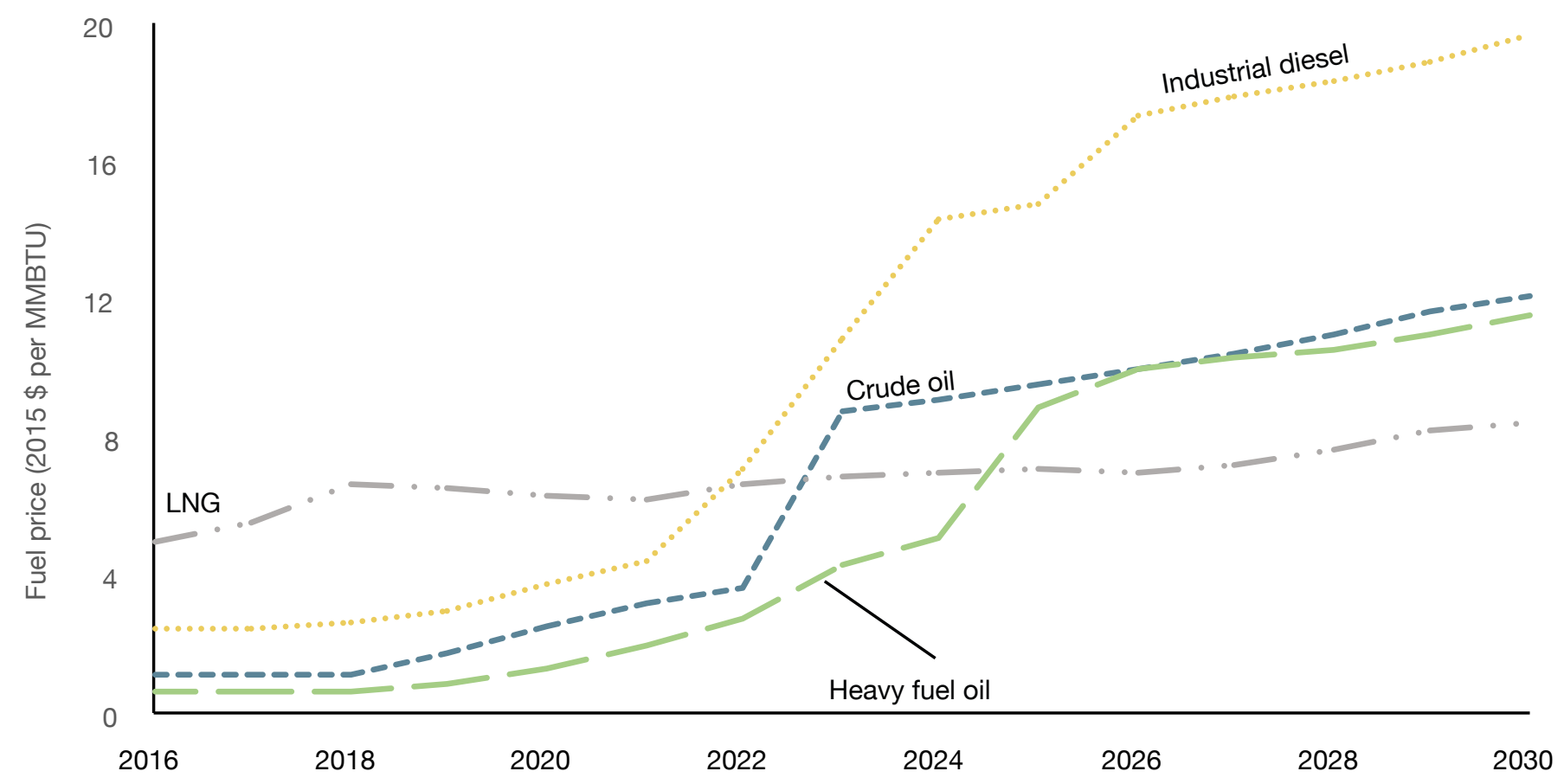

Source: KAPSARC analysis. 
period. The price of LNG imports is approximated using Nexant's World Gas Model (WGM) as the quarterly real Henry Hub price plus a flat liquefaction cost, a toll cost to pass through the Suez Canal, and a shipping cost that varies over time as a result of rising projected oil prices. The WGM contains a wide range of liquefaction costs depending on the facility. We estimate the liquefaction cost at $\$ 2.18 /$ MMBtu value, but the actual costs range from under \$2/MMBtu to nearly \$5/MMBtu.

The real international price and domestic production of crude oil, and the real gross outputs of the cement, petrochemical, and fertilizer industries are taken from Oxford Economics' Global Economy Model and Global Industry Model.

To calibrate the natural gas infrastructure, we use the inter-regional pipeline capacities as of 2015 , reported by the IHS Midstream database. The model is free to make decisions as to whether to increase pipeline investment thereafter. Appendix $C$ describes other model data and assumptions, including gas storage metrics.

The persistent utilization of fuel-fired plants that co-generate power and desalinated water as fuel prices are being raised is a contentious issue. Potable water demand in Saudi Arabia will increase as a result of higher population and the withdrawal or exhaustion of non-renewable domestic water resources. This may warrant the continual operation of co-generation plants, even if their use is costly.
To address this, we assume that existing water and power co-generation plants in the western and southern regions would receive crude oil and heavy fuel oil expenditure credits, such that the quantities of oil consumed in 2015 would still receive subsidized rates through the price reforms. This arrangement would allow them to operate economically, with the government bearing the cost of the credit. We have already taken into account the existing investment plans for power plants and desalination facilities, and any additional desalination plants built into the model account for higher fuel prices.

We do not include financial support for natural gas use in co-generation plants, as it is mostly used in the Eastern Province where the infrastructure may adjust more rapidly. This is due to the presence of Saudi Aramco and its mature gas infrastructure in that region. The construction lead times for reverse osmosis plants would be the only obstacle to overcome.

The Renewable Energy Project Development Office (REPDO), within MEIM, announced plans to deploy 9.5 gigawatts (GW) of solar photovoltaic (PV) generation, concentrated solar power (CSP) and on-shore wind turbines by 2023. Each plant, by technology and region, is input into KEM as planned installations, and we do not allow any more additions until 2023. The model is free to make renewable investment decisions beyond 2023. 


\section{Results and Discussion}

$\mathrm{T}$ The results of interest are the market-clearing prices of natural gas in the gas production cases, the levels and costs of regional storage of natural gas and its sectoral use, and any changes in investment decisions by the power utilities if more gas can be supplied in the summer beyond the daily cap. We will also comment on the effects that LNG imports would have on these results, and provide a cost-benefit assessment of the impact LNG imports would have on Saudi Arabia's power system and its energy system as a whole.

\section{The price of natural gas}

All of the natural gas currently used in Saudi Arabia is fulfilled by domestic production, as the country does not trade gas. The gas supply did not meet demand at the 2015 domestic natural gas price. Consequently, the government had to intervene by rationing the available quantity of gas. Figure 6 shows that the current price of natural gas of $\$ 1.25$ / MMBtu is in line with its market-clearing condition. This is because the price of the fuel substitute would be that of crude oil, which is currently $\$ 6.35$ per barrel. In the coming years, the domestic price of crude oil will rise with the prices of other potential fuel substitutes. Once crude becomes too expensive to use in the energy system, the price of natural gas will decouple from that of oil.

Due to the greater scarcity of natural gas in the low gas production case, its annual market-clearing prices would be noticeably higher than those of the high production case. The price in the low production case hovers around the LNG import price in the latter years of the period considered, indicating that some LNG imports may be made during this time. Under the high domestic gas availability case, the market-clearing price rises to around $\$ 4.50 / \mathrm{MMBtu}$ by 2024 and falls to around $\$ 1.50 / \mathrm{MMBtu}$ thereafter until 2030. The supply levels

Figure 6. The market-clearing price of natural gas for the high and low domestic gas supply scenarios until 2030.

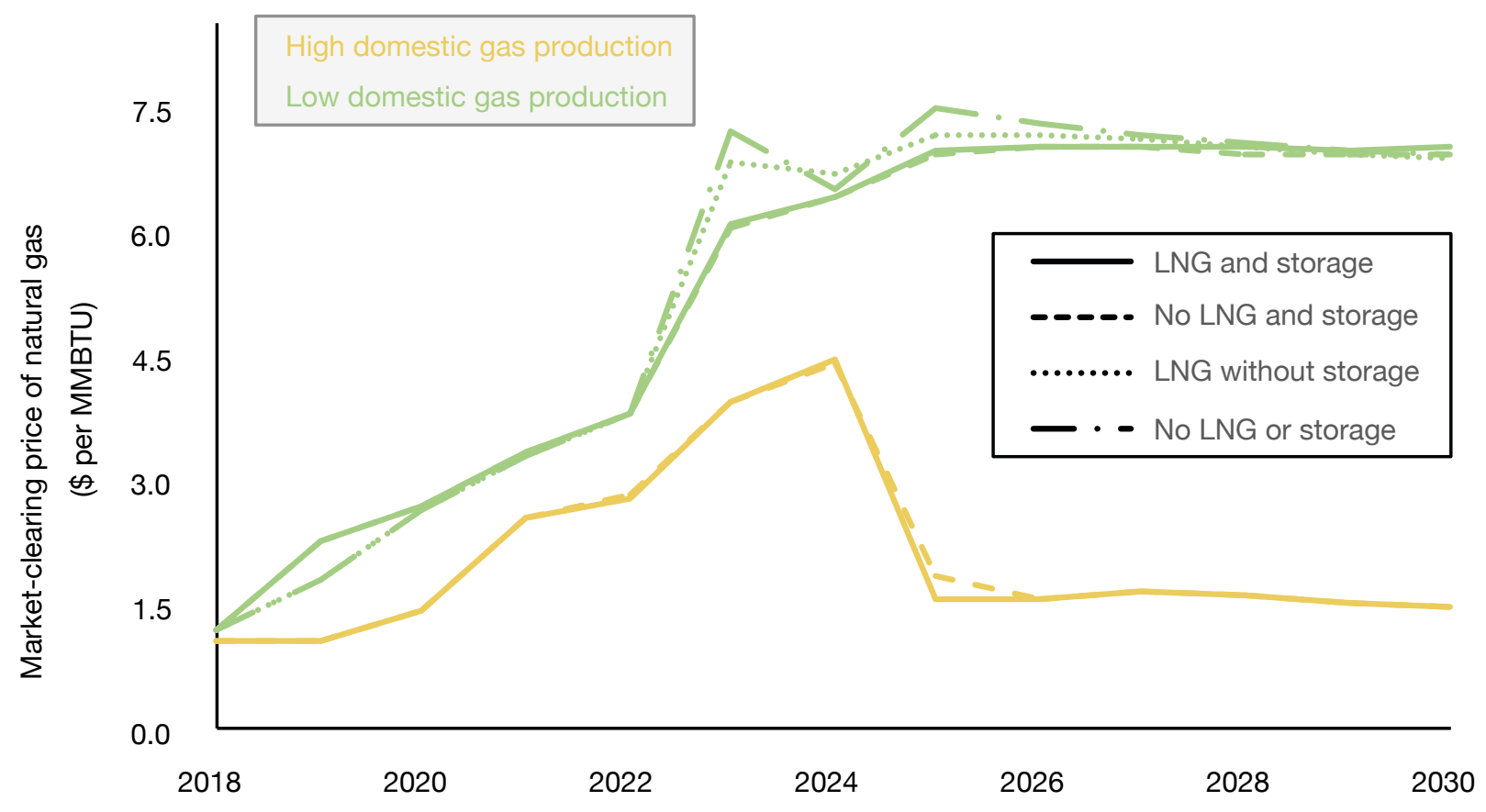

Source: KAPSARC analysis. 
from 2025 would constrain the Saudi economy, as in previous years. This is based on our assumptions for the projected power load and the demand from industry, as detailed in Appendix C. LNG imports would not be needed as there would be a high availability of gas. As such, we focus on the results of the two storage scenarios.

It can be seen that, in the low gas production case, a scenario with no gas storage and no importation of LNG would result in the highest market-clearing price for gas. This is because the country does not have alternative sources of gas or a means of storing it. A scenario with LNG imports but no gas storage achieves the second highest set of prices. Gas prices are almost equal in the scenarios with gas storage and those with and without LNG imports. The values converge by the end of 2030 to \$7/MMBtu for all policy options.

\section{Seasonal storage and use of natural gas by the power utilities}

If the high natural gas production case is realized, the transport limit for gas still constrains the power system during the summer. Thus, even when gas is inexpensive, we see investment in renewable power. Due to the transport limit, natural gas storage facilities store up to 37 trillion Btu (36 Bcf) of natural gas in the early to mid-2020s. These facilities are built in the western and southern areas of the country, which do not have mature gas infrastructure. Once installed, these storage facilities would displace about 300 megawatts (MW) of PV capacity by 2030. No LNG imports would be made in the high production case, as indicated by the market-clearing prices. The amount of domestically sourced natural gas would be sufficient to meet the domestic demands from the power and manufacturing sectors in the summer.
The value of alleviating this transport constraint can be viewed as the dual variable of the constraint itself, as discussed in Appendix A. The variable shows how much the power system would reduce its total cost by, by allowing one more unit of natural gas to be transported to power plants. Without storage, the cost to the power system in the high production case is $\$ 342 / \mathrm{MMBTU}$ per day in 2030 , against $\$ 43 / \mathrm{MMBtu}$ per day with storage.

Natural gas storage may still be favorable for consuming sectors in a low gas production environment. In this case, the gas transport limits in the summer would not be an issue. There is barely enough gas for the combined operation of power producers and other sectors in the summer. Hence, storage facilities are required to facilitate the efficient use of gas among industries throughout the seasons. 'Efficiency' in this context means the flexibility to produce gas in one season or year to meet the demand in another period.

The model results show that storage in the low production case is primarily built in the eastern, central, and western areas of Saudi Arabia. There is about 1,900 trillion Btu (1,832 Bcf) of gas storage nationally by 2022 , at the cost of $\$ 11.5$ billion; the same capacities are built with and without LNG imports. Figure 7 shows the stored natural gas, nationwide, through the seasons for the low gas production case. There is a negligible difference between both LNG scenarios.

The quantity of stored gas may be distributed to the power system or the other industries modeled in KEM. We whittle down the scenarios to four to look at the differences in power plants' national utilization of gas: LNG imports with and without natural gas storage for low and high gas production, as shown in Table 1. 
Figure 7. Stored natural gas by the oil and gas upstream sector with and without LNG imports, for the lower gas production case.

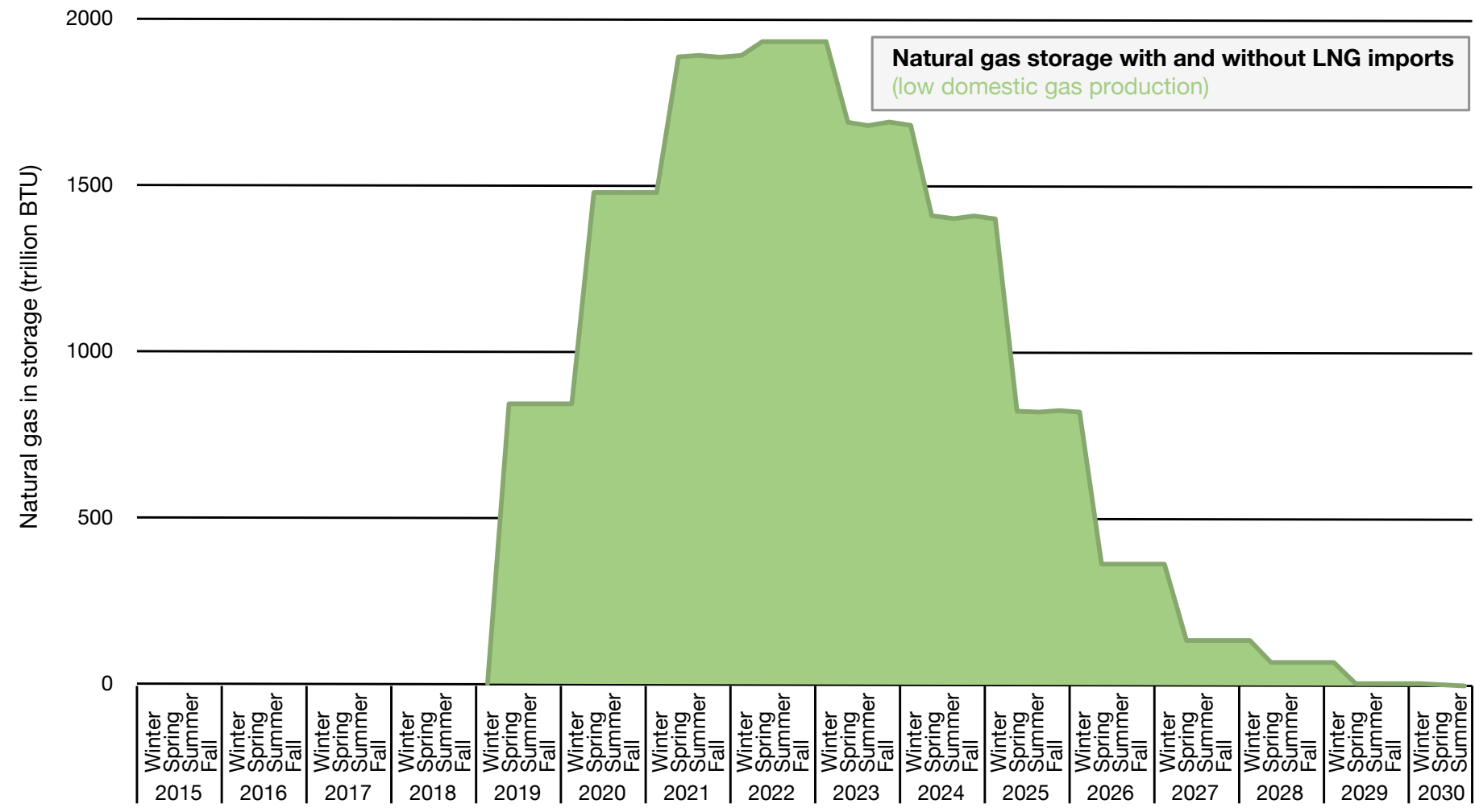

Source: KAPSARC analysis.

Figures 8-11 illustrate seasonal gas use by power producers until 2030 for the four scenarios. Nothing unexpected takes place under the high gas production scenario. A scenario with storage allows the power sector to use a little more domestic natural gas in the summer until 2030. Gas use growth is dampened towards the end of the period considered by the gradual displacement of steam turbine plants with more efficient combined-cycle plants.

With LNG imports, major differences in domestic gas use by the power utilities in a low gas production case with and without storage take place in 2019-2021, 2025, 2026, and 2028. In 2019-2021, the power sector forgoes the use of natural gas in preference for later years when there is gas storage. Fuel prices are still low enough in 2019-2021 for the sector to use more crude oil cost-effectively. In 2025 and 2026 without gas storage, the power utilities would exploit the availability of LNG to allow the domestic use of gas in other sectors. Overall, the power sector lessens its summer gas use in the late 2020s because there are more PV and CSP plants due to their declining costs. As Figure 8 shows, without natural gas storage, the decline in gas use from the summer of 2026 until the summer of 2030 is sharper than that in the winters.

Another metric, represented by Equation 1 and illustrated in Figure 12, takes the gas consumption by the utilities $(G)$ in the two high gas production scenarios and presents the differences in their annual summer-to-winter swings of gas use. We use this metric for the high gas supply scenarios because 
storage is, in these cases, built to mitigate the impact of the transport limit. A positive value of the change in seasonal gas use indicates the seasonal swing for the scenario with storage is larger than the one without. The value is significantly positive after the mid-2020s, with the difference between the two scenarios rising until 2030. Gas storage would allow power utilities to use more gas in the summer compared to a situation without storage. The reduced use of gas in 2021 is due to the model storing natural gas that year in favor of using it in subsequent years.

$$
\begin{aligned}
& \varphi_{\text {year }}=\left[\left(G_{\text {summer }}-G_{\text {winter }}\right)_{\text {with storage }}-\right. \\
& \left.\left(G_{\text {summer }}-G_{\text {winter }}\right)_{\text {without storage }}\right]_{\text {year }}
\end{aligned}
$$

There is a higher swing between summer and winter from 2015 to 2030 of, in aggregate, about 220 trillion $\mathrm{Btu}(0.6 \mathrm{Bcf} / \mathrm{d})$. The solution is sensible given that gas storage facilities would use more natural gas in the summer months when the transport limit would be binding, and that power utilities would only invest slightly less in renewable capacity. So gas storage widens the annual swings in the utilities' gas use.

Natural gas not used by power plants in the winter would be used to produce fertilizer for export.

Fertilizer exports would be constrained in the summer as power producers would use more natural gas. We can question whether this result is sensible. Will global demand for fertilizers be concentrated in the winter? This model is only for Saudi Arabia, so we do not tackle global equilibrium effects.

Figure 8. Seasonal utilization of natural gas by power plants without gas storage but with LNG imports, for low gas production.

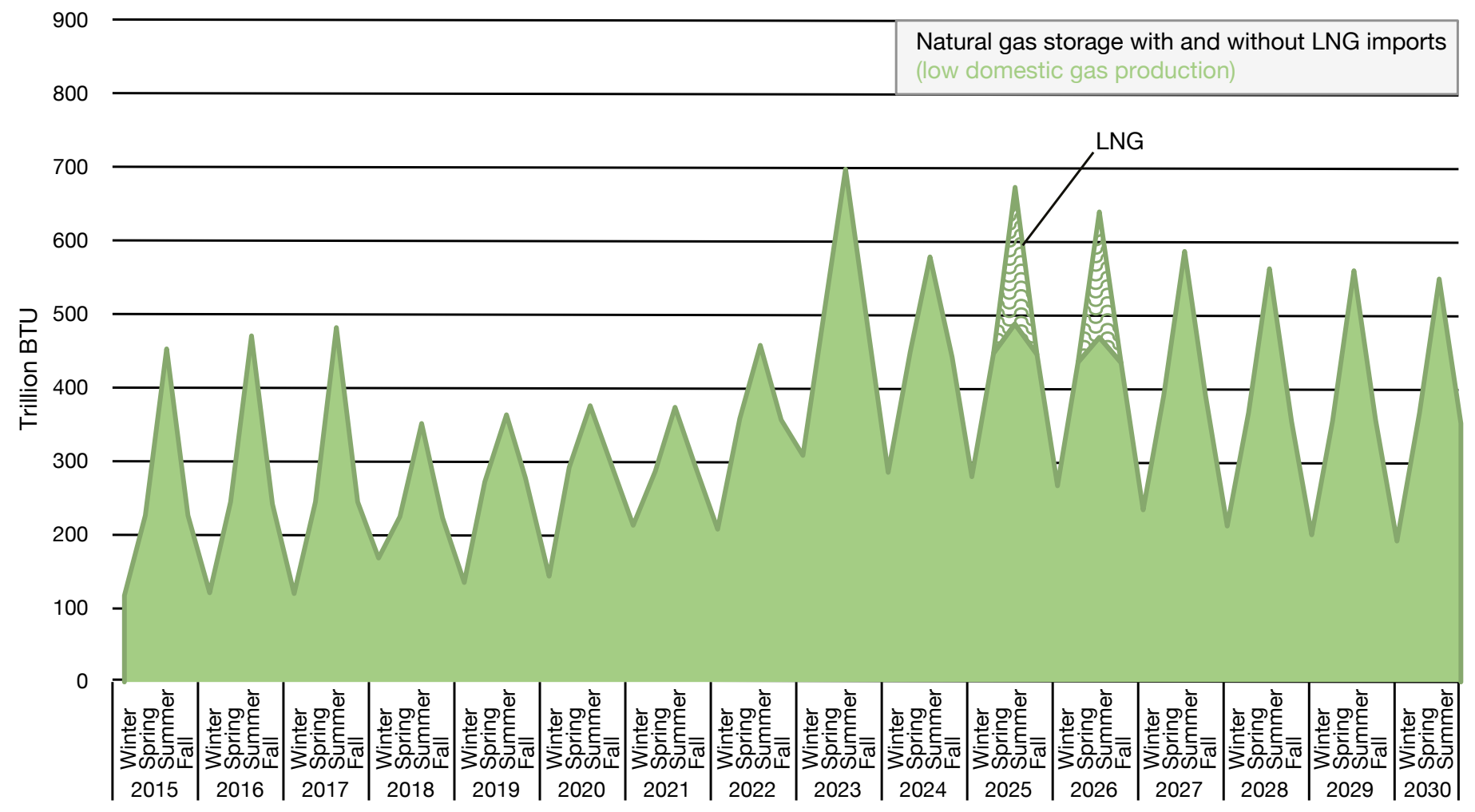

Source: KAPSARC analysis. 
Figure 9. Seasonal utilization of natural gas by power plants with gas storage and LNG imports, for low gas production.

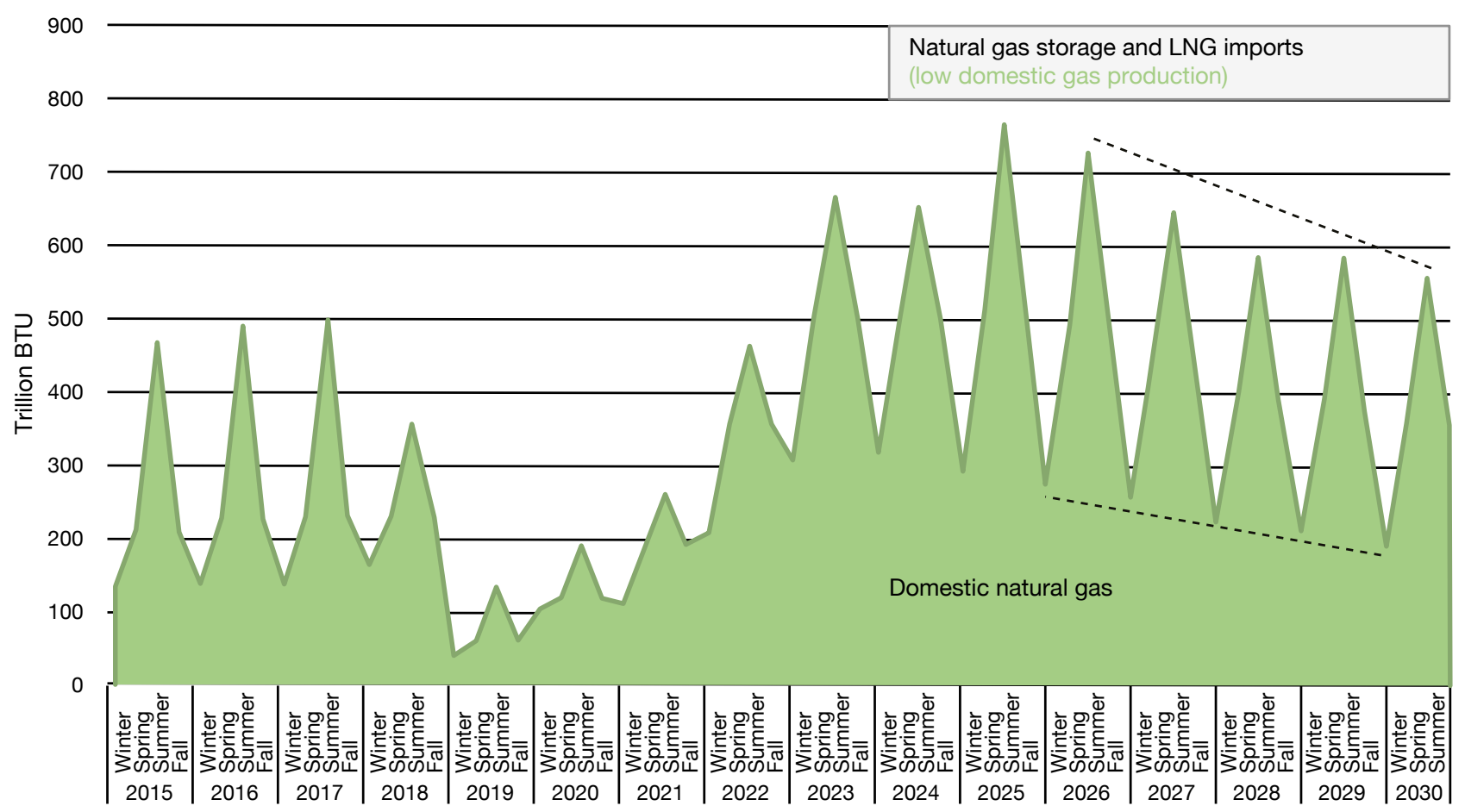

Source: KAPSARC analysis.

Figure 10. Seasonal utilization of natural gas by power plants without gas storage but with LNG imports, for high gas production.

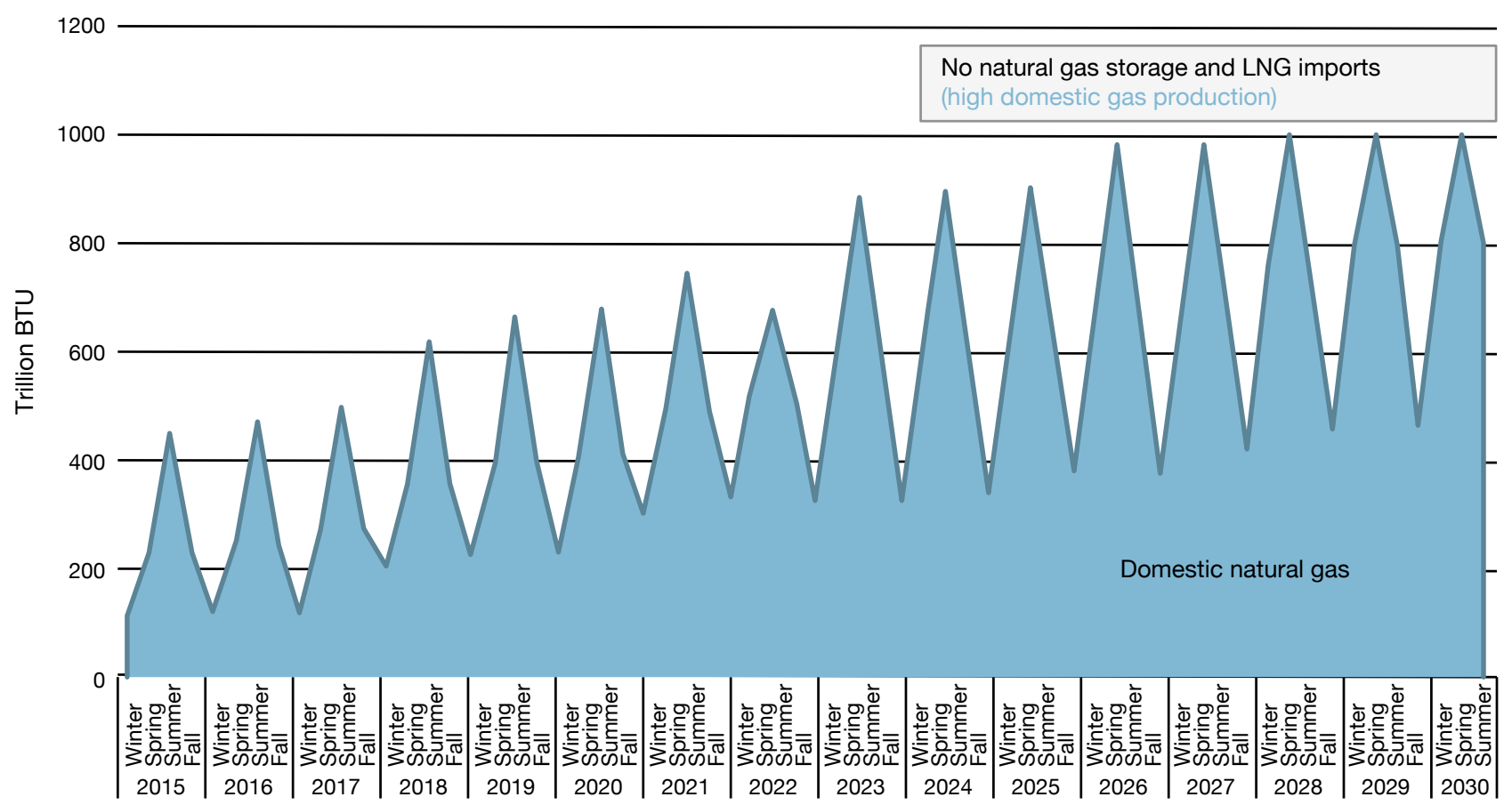

Source: KAPSARC analysis. 
Figure 11. Seasonal utilization of natural gas by power plants with gas storage and LNG imports, for high gas production.

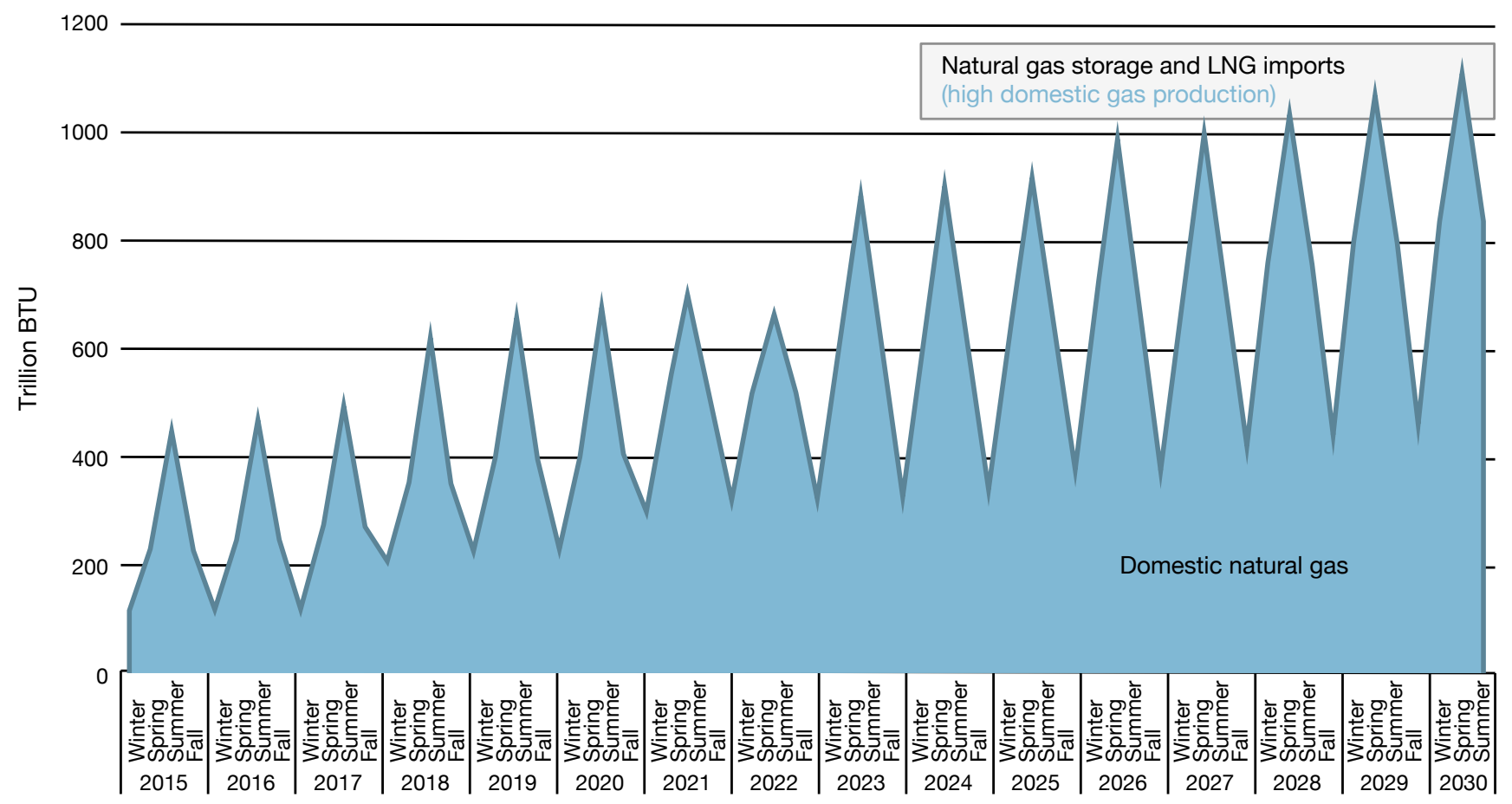

Source: KAPSARC analysis.

Figure 12. Differences in annual swings in the use of domestic natural gas by power plants between scenarios with and without gas storage, for the high domestic gas production case.

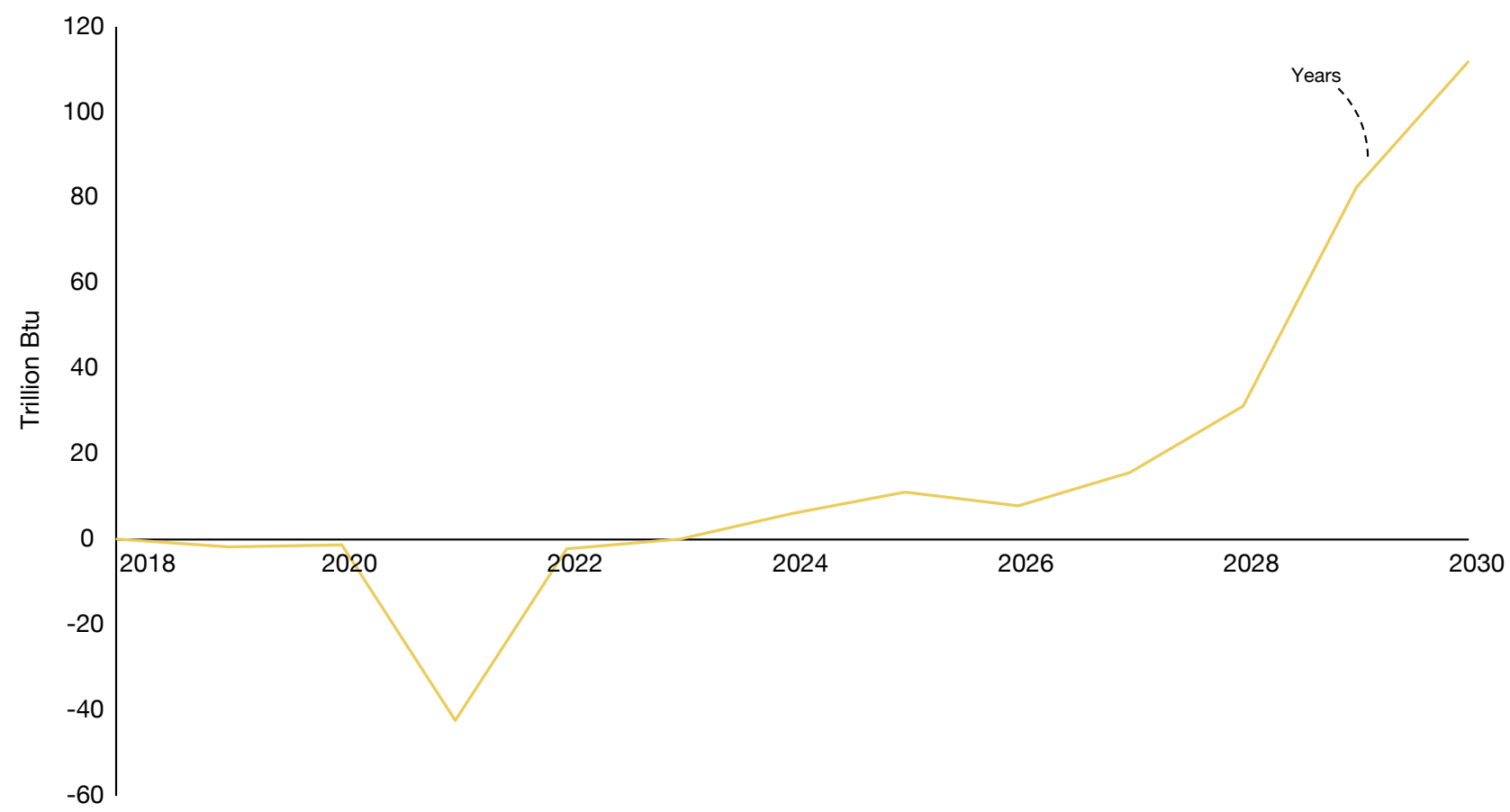

Source: KAPSARC analysis. 
Power utilities would not import LNG if the high gas production case materialized. With low gas production, power plants would use 400 trillion Btu (8 million tonnes) of LNG with no gas storage facilities built, versus no LNG being used with storage. LNG is predominantly imported in the summer months and used in the western and southern areas of Saudi Arabia. Stored domestic gas would therefore replace nearly $\$ 3$ billion of imported fuel. Greater quantities of LNG were imported in KEM after the model was modified to consider seasonal fuel prices. The results are also highly sensitive to the liquefaction cost assumption. For example, LNG cannot compete with renewable technologies if the plant of origin liquefies at $\$ 2.73 / \mathrm{MMBtu}$.
The savings in the low gas production case extend beyond lower fuel costs for the power system; it also reduces the need to build new generation capacity. With natural gas storage, the power sector would spend $\$ 700$ million less on new capacity between 2015 and 2030 than in a situation with no storage, mainly from deferred investment in PSSH. LNG imports are subdued because higher LNG prices outside the summer months make renewable generation less expensive year-round. Figures 13 and 14 illustrate the hourly power generation profiles of national power plants in the summer of 2030. Whether or not UGS facilities are built has no bearing on how power plants operate in the low supply case. PSSH would only be used as backup generators for PV and wind turbine plants.

Figure 13. Power generation profiles by plant technology on a summer weekday of 2030 without gas storage, for the low gas production case.

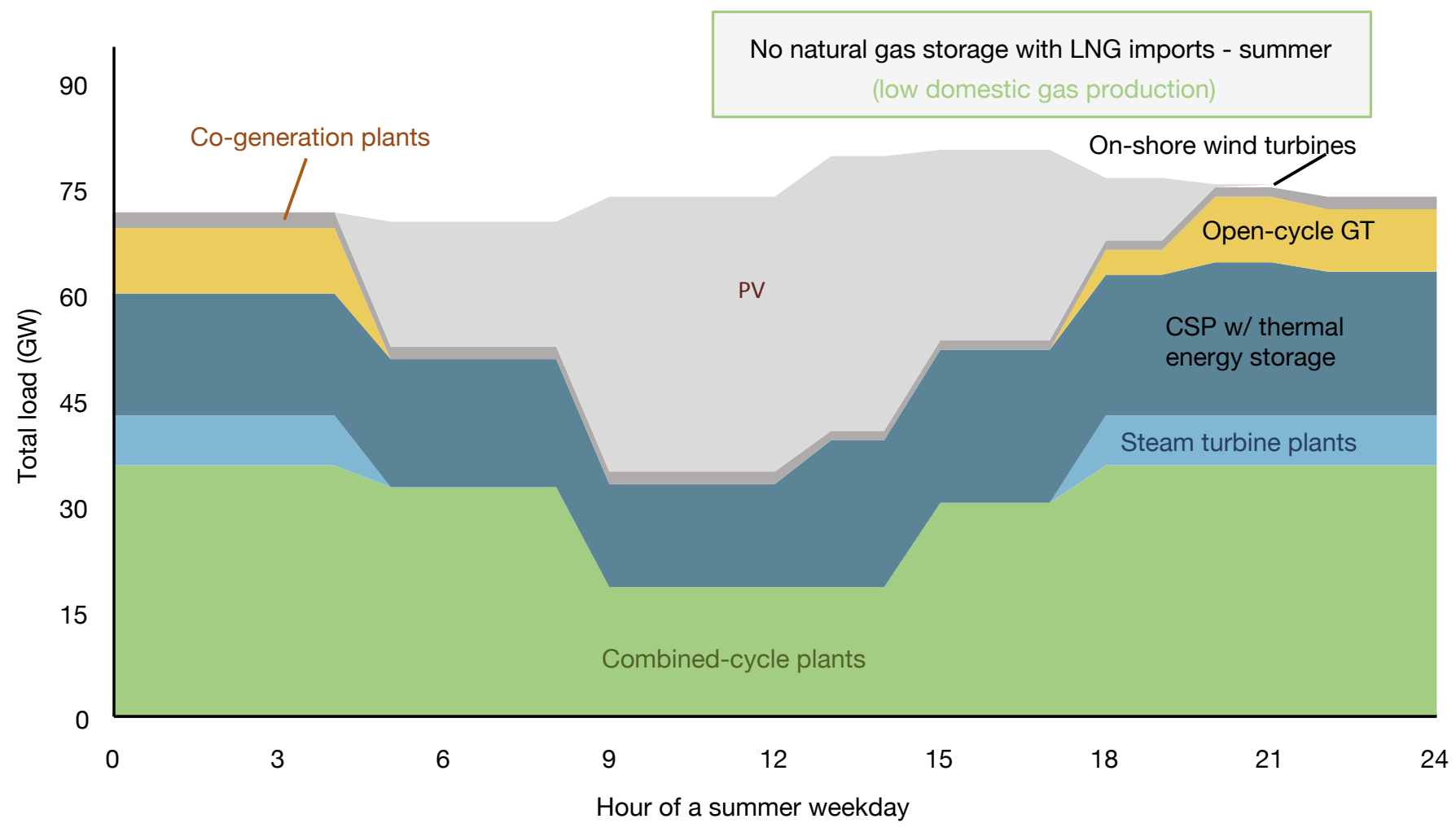

Source: KAPSARC analysis. 
Figure 14. Power generation profiles by plant technology on a summer weekday of 2030 with gas storage, for the low gas production case.

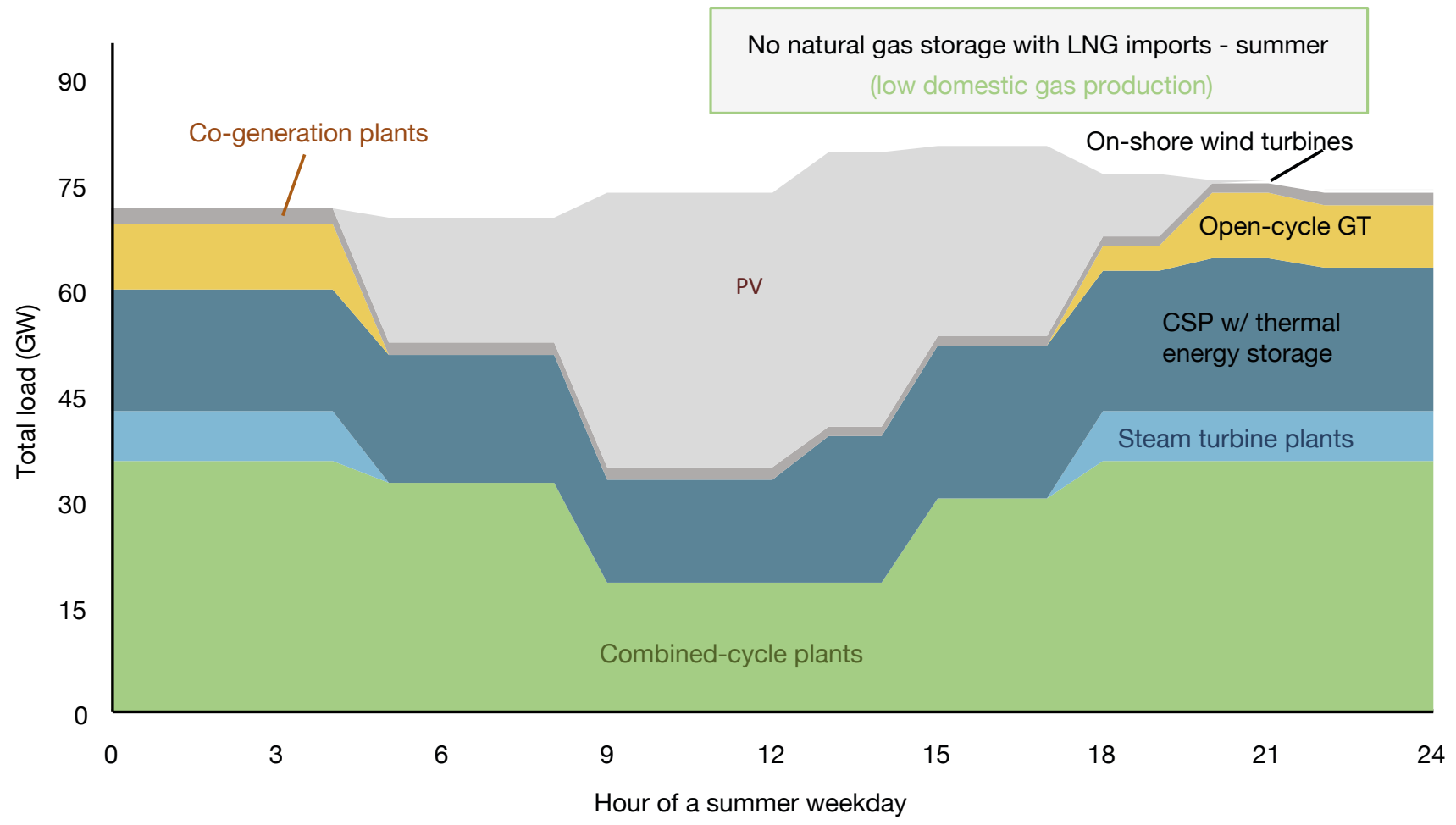

Source: KAPSARC analysis.

Figure 15. Power generation profiles by plant technology on a summer weekday of 2030 without gas storage, for the high gas production case.

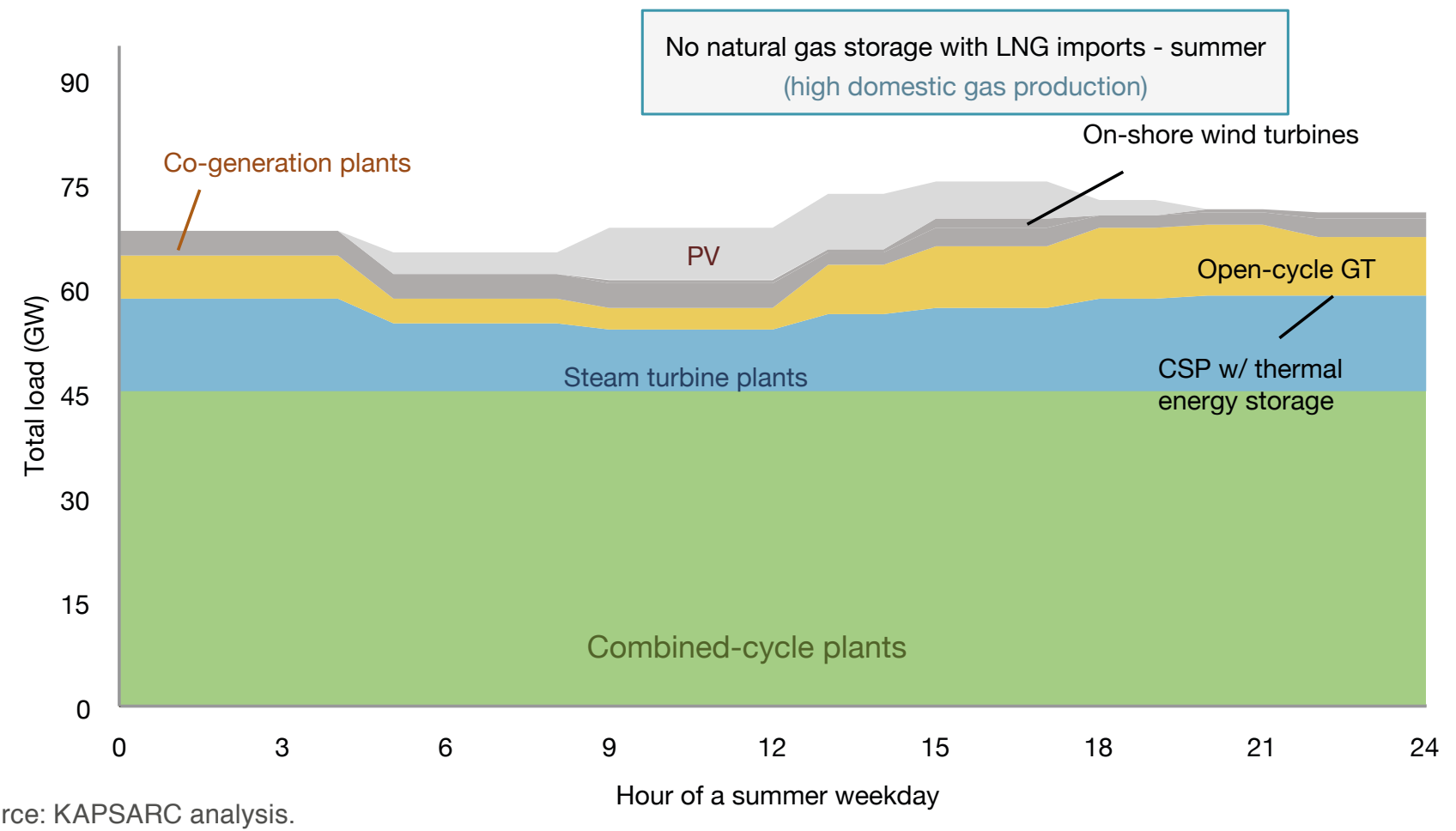

Source: KAPSARC analysis. 
Figure 16. Power generation profiles by plant technology on a summer weekday of 2030 with gas storage, for the high gas production case.

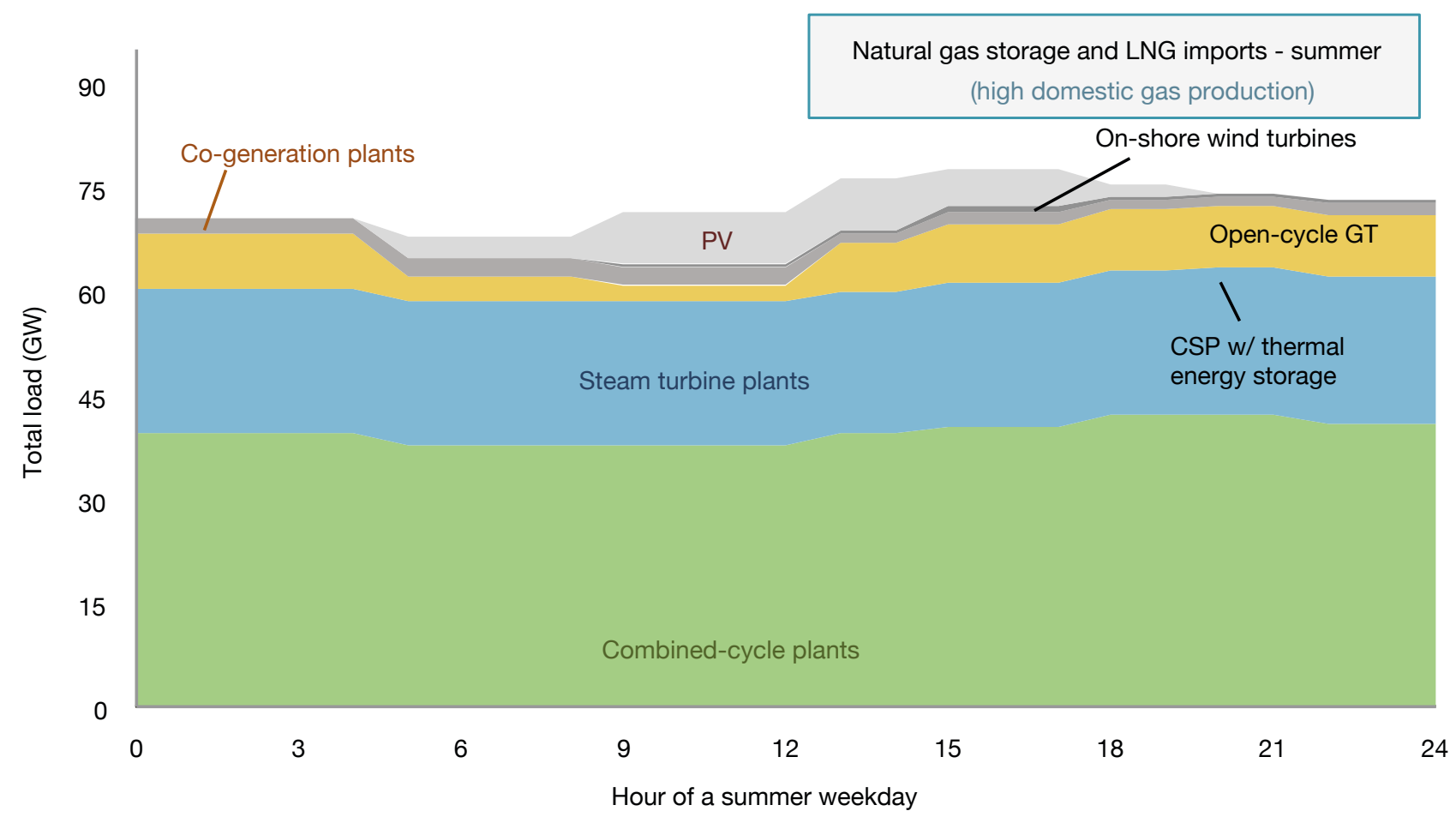

Source: KAPSARC analysis.

Figures 15 and 16 show that in the high production case, additional thermal co-generation desalination plants are used with no UGS. Co-generation plants would normally not be used at all, but since some can receive the fuel credits discussed earlier, they are considered economical. So less oil would be used in the case with UGS because more gas-fired power plants would be able to run. More gas-fired steam turbine plants are utilized when UGS is used in place of combined-cycle plants. In this sense, the advent of UGS makes enough gas available to warrant not investing in combined-cycle plants in favor of existent, albeit less efficient, steam turbine plants. About $300 \mathrm{MW}$ of PV generation capacity is crowded out as a result of UGS. The lower deployment of renewable technologies is attributed to higher gas availability at lower prices.

We observe $48.8 \mathrm{GW}$ of PV, 24.5 GW of CSP, and $2.4 \mathrm{GW}$ of on-shore wind turbines by 2030 with low gas production and UGS, and $10 \mathrm{GW}$ of PV, 0.3 GW of CSP, and 2.4 GW of on-shore wind turbines with high gas production. These renewable generation capacity builds are based on the least-power-system-cost solution for each scenario. Other hurdles may arise, however, such as capital constraints, and the renewable capacity additions may turn out to be less than forecast. This is especially true for the low gas production case, and it may result in other generation options being chosen. If renewable generation is reduced, more LNG- or heavy fuel oil-fired electricity, or even nuclear power, may be dispatched. The high gas production case results in $3.2 \mathrm{GW}$ more renewable capacity than in REPDO's plans. The levels of renewable generation in Saudi Arabia are highly dependent on domestic gas production.

Between 10 and 14 GW of PSSH would be built in the two gas production cases. Although PSSH 
does not meet electricity demand, the power sector still invests in the technology to provide a backup for renewable technologies. Interestingly, because the model deploys more CSP without gas storage in a low gas production case, there is less need to generate electricity using PV in some instances; this reduces the need for $\mathrm{PSSH}$ as a backup.

So while it is true that building natural gas storage would result in higher costs for the oil and gas sector, the cost to the power system would decline, along with electricity prices for end-users if they were cost-reflective.

\section{Use of natural gas by the major industries in Saudi Arabia}

Natural gas would be primarily used for power generation by 2030 , with the remaining gas consumed by industrial production. The petrochemical, fertilizer, and cement industries are the largest gas-consuming industries in the country. Figure 17 shows the aggregated seasonal gas use by those industries for the low domestic gas production case, imported LNG, and with and without gas storage. Figure 18 shows this series for the high gas production case.

There is a high demand for natural gas during the summer from local power producers. Manufacturing industries mostly meet the domestic demands for their goods in the summer and use the scant remaining quantities of gas for petrochemical, fertilizer, and cement exports. Seasonal volatility in gas use is exacerbated without gas storage before 2020. The installation of storage may provide a steadier stream of natural gas to petrochemical and fertilizer producers, especially in the low gas production case.

Figure 17. Seasonal natural gas use by petrochemical, fertilizer, and cement manufacturers, for low gas production.

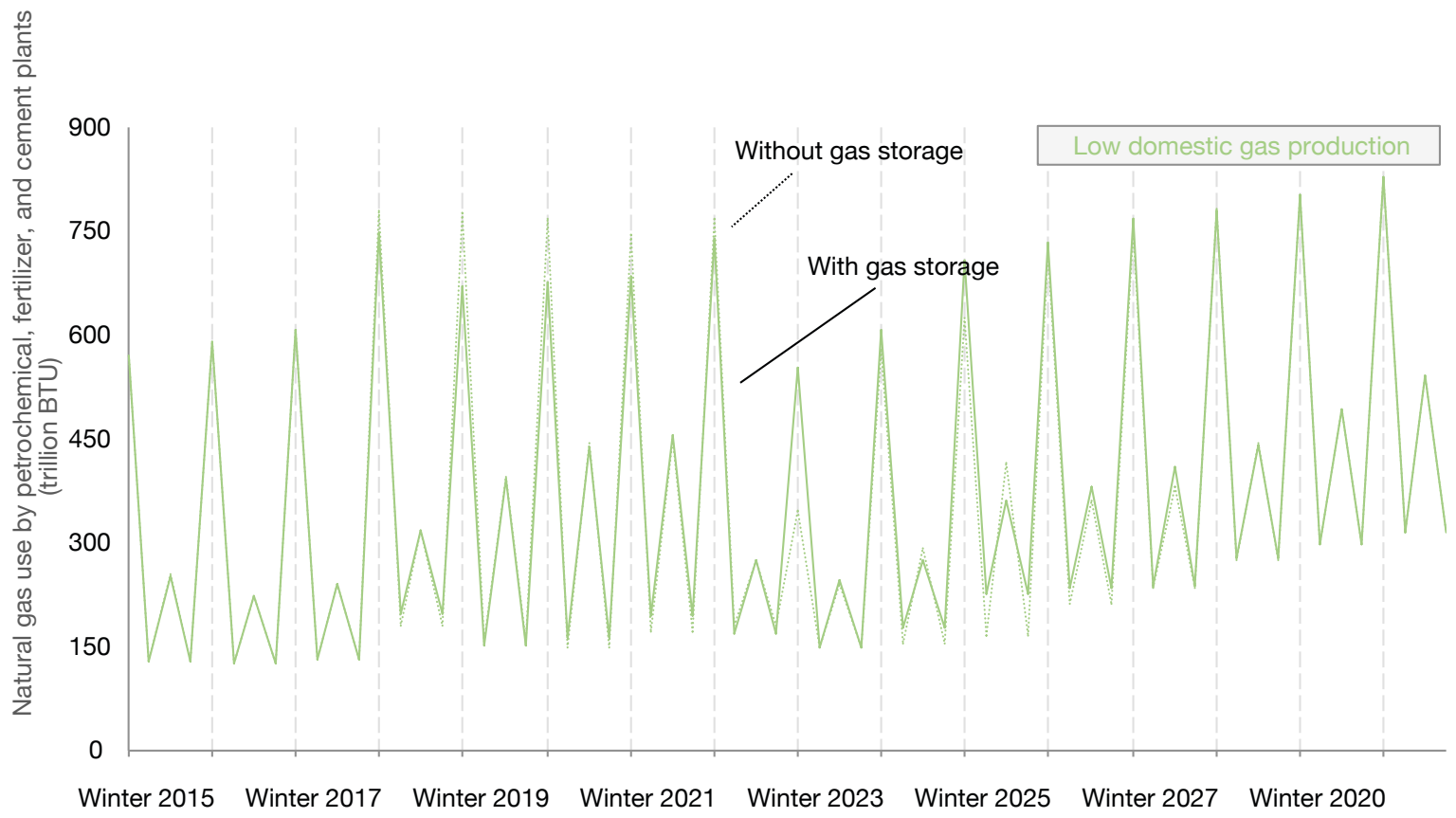

Source: KAPSARC analysis. 
Figure 18. Seasonal natural gas use by petrochemical, fertilizer, and cement manufacturers, for high gas production.

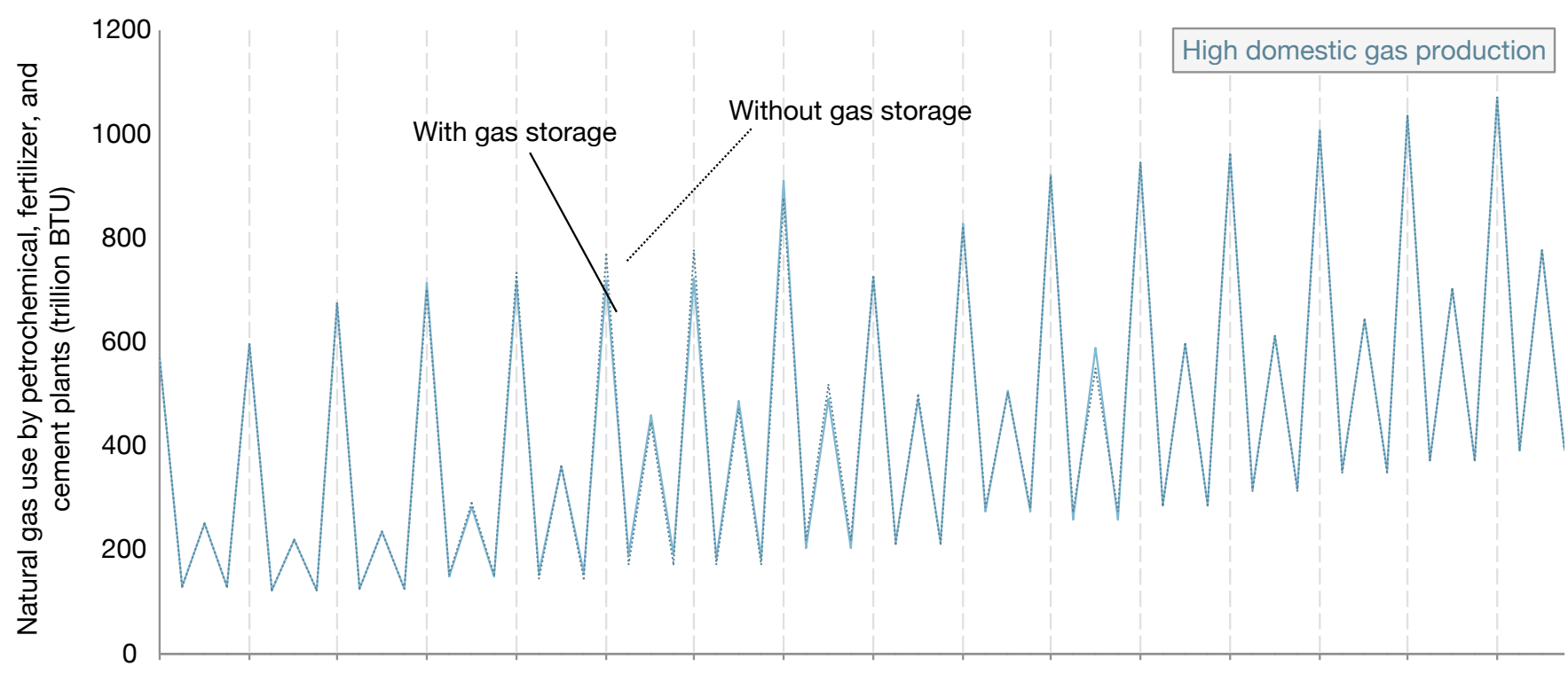

Winter 2015 Winter 2017 Winter 2019 Winter $2021 \quad$ Winter $2023 \quad$ Winter 2025 Winter $2027 \quad$ Winter 2029

Source: KAPSARC analysis.

During the winter months, when the domestic demand for electricity has subsided, more gas supply is made available for petrochemical and fertilizer producers, and exports become their primary operational motive. The majority of the exports in the winter are natural gas-based fertilizers. Petrochemicals rely on ethane and other liquids for feedstock, although some natural gas is used as a fuel for some processes. Ethane and propane do not have the multi-sector uses of natural gas (methane). Gas use dips in 2023, with the power system requiring more gas as a result of making oil products more expensive.

Higher costs of petrochemical and fertilizer production, brought upon by higher gas and ethane prices, will require more downstream production, bulk chemicals like ethylene and propylene, and higher-value chemical products to improve companies' profitability. This move supports the use of natural gas by power plants: going further downstream, beyond the initial steam cracking stage, requires more electricity as opposed to hydrocarbon feedstock.

With increasing fuel prices, cement manufacturers still using long-dry kilns could well shift their operation to more efficient kilns with precalciners and preheaters. In addition, the presence of gas storage facilities would give them greater flexibility on both ends of their production process: on the supply side with greater flexibility surrounding fuel use, and on the demand side with the ability to store their products. It is apparent from the results that gas storage does not change the cement industry's annual use of gas. However, there are seasonal differences in the industry's use of gas, particularly in the low supply case. 


\section{Assessing the economic viability of natural gas storage}

We have discussed the effects of the combination of LNG imports and natural gas storage on the decisions of the major gas consumers in Saudi Arabia. We now use a measure to quantify the financial viability of each policy scenario to the energy system.

The real annual economic gain is the annual value of the netted export revenue of all sectors in the energy system minus the netted total costs incurred, relative to the reference scenarios. The revenues and costs considered for the energy system are cash flows that 'cross the boundary' of the energy system defined by KEM. The reason we consider only export revenues is because all exogenous domestic demands are fixed. Therefore, the difference in revenues accrued domestically between a reference scenario and an alternative scenario is zero. The reference scenarios in this analysis do not have natural gas storage or LNG imports.

We further define the net present value for the economic gain in 2018 as the discounted sum of the annual gain values until 2030 , using a real social discount rate of $5 \%$. This metric may be used to assess the viability of storage facilities. If the present value is positive and large with gas storage in place, we can conclude that this option is worth pursuing.

The high production case with gas storage yields a net present economic gain of almost $\$ 900$ million relative to the reference case with no storage and no LNG imports. Moreover, Figure 19 shows the

Figure 19. Net present economic gains for the energy system, for the low gas production scenarios.

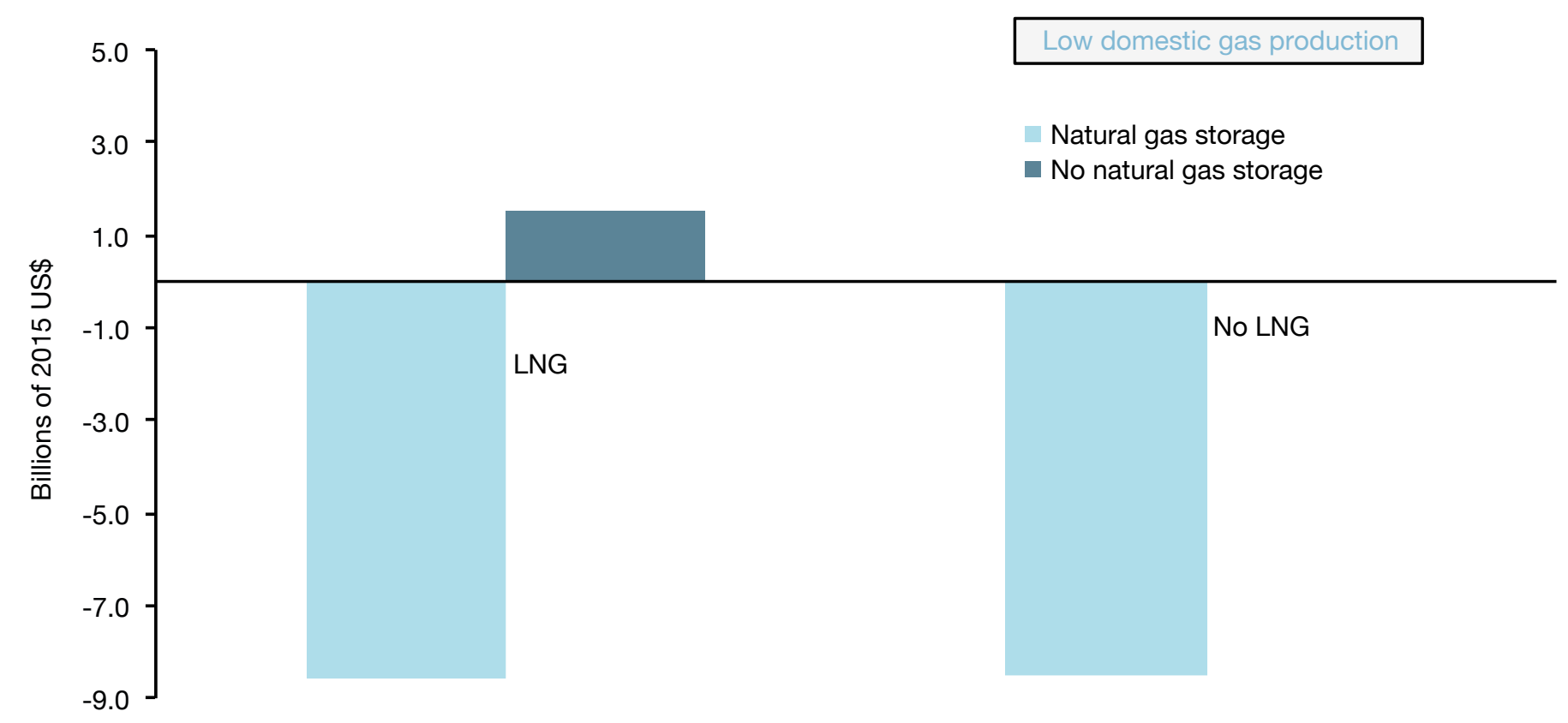

Source: KAPSARC analysis. 
discounted economic gain for all low gas production scenarios. The scenario with the highest net benefit, minus costs, is one that allows for LNG imports alone. Adding the possibility of gas storage provides a negative measure (as a reminder, there would no LNG imports with UGS). In the lower production case, the construction of storage facilities is economically unattractive for the whole energy system. However, it may still provide a positive economic gain for the power sector. Measuring the above metric for the power system alone involves its sales revenue and its total fuel, non-fuel operational, and investment costs. Although the sales revenue primarily involves a fixed consumption of electricity between scenarios, the endogenous demand of industrial sectors in KEM may change in different policy scenarios, especially given that the petrochemicals sector is shifting further downstream. Figure 20 shows the net present gain for the power system for the low production case, discounting by the same real rate from 2018 until 2030 , as with the calculation for the energy system.
Overall, the power system gains exhibit positive signs for all alternative scenarios. As a reminder, in the low gas supply case, the gas-consuming sectors of the Saudi economy would face the lowest natural gas price with gas storage. The low price of natural gas, and the reduced need for investment in PSSH plants, would mean that the storage option generates the largest gain for the power sector. For the low production case, the gain with UGS (nearly $\$ 4$ billion) is not simply the sum of the gains for each option. The net present gain for the power sector in a high gas supply case would be almost $\$ 0.5$ billion.

The difference between the system-wide and sectoral-level economic gain reveals the benefit of a system-wide analysis. The power sector would benefit the most from having both gas storage and LNG imports, whereas the entire energy system would benefit the most from having LNG imports alone. This is primarily because the upstream sector would bear the investment and operational costs of gas storage.

Figure 20. Net present gains for the power system, for the low gas production scenarios.

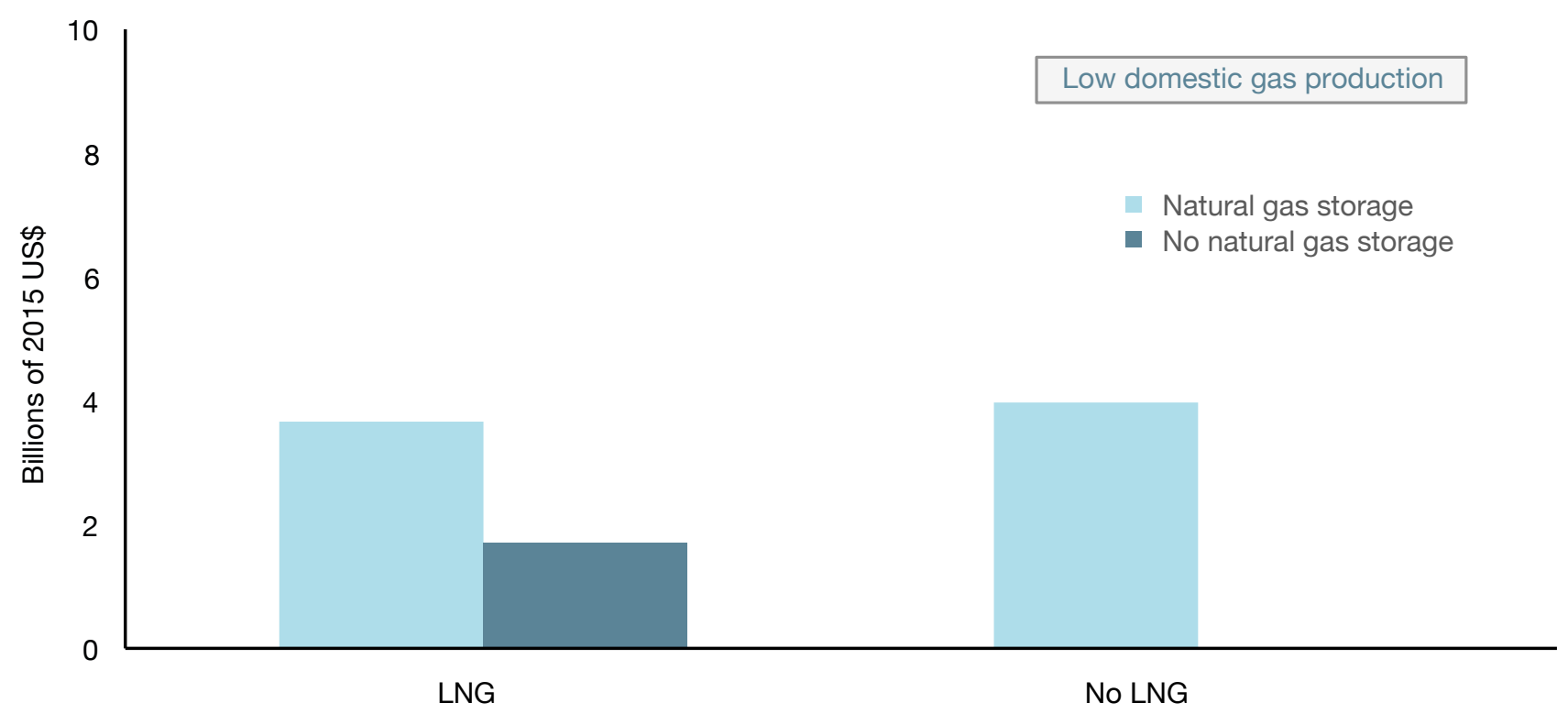

Source: KAPSARC analysis. 


\section{Conclusion and Policy-Relevant Insights}

aking a gradual increase of industrial fuel prices into consideration, this analysis

assesses the viability of seasonal natural gas storage in Saudi Arabia. Current plans call for the expansion of natural gas connectivity to power producers. These plans are separate from any plan to increase domestic gas production overall. Multiple scenarios are examined: two sets of domestic natural gas supply projections, whether or not the country allows the import of LNG, and whether or not the oil and gas upstream sector is allowed to construct gas storage facilities.

We conduct this analysis by using an updated version of the KAPSARC Energy Model, which includes a daily transport limit for natural gas to power plants, and seasonal operation for the petrochemical, fertilizer, and cement industries, among other new features.

If the limit on the transportation of gas is binding, natural gas storage would hypothetically offer the ability to use the spare pipeline capacity in the winter to transfer gas to storage facilities. The stored natural gas could then be used in other seasonal periods as needed. Power utilities and manufacturing sectors would be able to take advantage of this added seasonal dimension.

Taking the period 2018 to 2030 , and the high supply case, the energy system would realize a discounted net economic gain of nearly $\$ 900$ million with gas storage. Gas storage would extend the power sector's summer-to-winter swing in its gas use by 112 trillion $\mathrm{Btu}(0.3 \mathrm{Bcf} / \mathrm{d})$ in 2030. Hence, gas storage ultimately widens the seasonal swing, as it allows more gas to be used beyond the transport limit; only $300 \mathrm{MW}$ of renewable power capacity is deferred.

Conversely, if gas supply projections were pessimistic, the energy system would only realize a positive gain if LNG is imported. The value of the discounted sum of net annual gains is $\$ 1.5$ billion. In this case, the power system would enjoy larger gains with storage, regardless of LNG imports, but the costs of the storage facilities for the oil and gas upstream sector would exceed the benefits attained by the power system. The benefits of gas storage to the power sector would include a lower natural gas price and almost $1 \mathrm{GW}$ of deferred investment in PSSH capacity. In comparison, no LNG would be imported in a case with high domestic gas availability.

While industrial gas use is not significantly altered as a result of gas storage, it would see greater swings in seasonal gas use for the low gas supply case. Even then, it only experiences different usage patterns from the early to mid-2020s. We also notice the high utilization of gas in the winter to accommodate the large demand for electricity in the summer months. 


\section{References}

Alyousef, Yousef, and Paul Stevens. 2011. "The cost of domestic energy prices to Saudi Arabia." Energy Policy 39(11): 6900-6905. DOI: https://doi.org/10.1016/j. enpol.2011.08.025

Baldick, Ross, Udi Helman, Benjamin F. Hobbs, and Richard O'Neill. 2005. "Design of Efficient Generation Markets." Proceedings of the IEEE 93(11): 1998-2012. DOI: https://doi.org/10.1109/jproc.2005.857484

Cedigaz. 2017. "Underground Gas Storage in the World 2017 Status."

Deane, J.P, B.P. Ó Gallachóir, and E.J. McKeogh. 2010. "Techno-economic review of existing and new pumped hydro energy storage plant." Renewable and Sustainable Energy Reviews 14: 1293-1302. DOI: https://doi. org/10.1016/j.rser.2009.11.015

Denholm, Paul, Jennie Jorgenson, Marissa Hummon, Thomas Jenkin, David Palchak, Brendan Kirby, Ooki Ma, and Mark O'Malley. 2013. "The Value of Energy Storage for Grid Applications." National Renewable Energy Laboratory (NREL) TP-6A20-58465. DOI: https://doi. org/10.2172/1220050

Electricity \& Co-Generation Regulatory Authority (ECRA). "Revised Generation Planning Report: Electricity Generation and Transmission Plan (EGTP)" King Fahd University of Petroleum and Minerals Research Institute: 3-6.

Energy Information Administration (EIA). 2018a. "Natural Gas Consumption in the United States." Accessed Apr. 28, 2018. http://www.eia.gov/oil_gas/natural_gas/data_ publications/natural_gas_monthly/ngm.html

- - - 2018b. "Table 2.4 Industrial Sector Energy Consumption." Accessed May 17, 2018. https://www.eia. gov/totalenergy/data/browser/xls.php?tbl=T02.04.

- - - 2015. "EIA now reporting monthly base gas levels in underground natural gas storage." Accessed May 15, 2018. https://www.eia.gov/todayinenergy/detail. php?id=22092
Federal Energy Regulatory Commission. 2004. "Current State and Issues Concerning Underground Natural Gas Storage." Docket No. AD04-11-000: 18-19.

Folle, Stefan. 2006. "Middle East Salt deposits Distribution and potential use." Technical Conference Paper, Brussels: Solution Mining Research Institute.

Hale, Elaine, Brady Stoll, and Trieu Mai. 2016. "Capturing the Impact of Storage and Other Flexible Technologies on Electric System Planning." NREL Technical Report NREL/TP-6A20-65726: 21-23. DOI: https://doi. org/10.2172/1253712

Hinchey, Nathalie. 2017. "Estimating Natural Gas Salt Cavern Costs." Houston: Rice University.

Husseini, Moujahed I., and Sadad I. Husseini. 1990. "Origin of the Infracambrian Salt Basins of the Middle East." Geological Society London Special Publications 50(1): 279-292. DOI: https://doi.org/10.1144/gsl. sp.1990.050.01.14

ICIS. 2013. "New focus: Saudi ethane price hike would erode petrochemical competitive advantage." Accessed May 24, 2018. https://www.icis.com/resources/ news/2013/04/15/9658366/news-focus-saudi-ethaneprice-hike-would-erode-petrochemical-competitiveadvantage/

Jaju, Marwan, Fadi Henri Nader, François Roure, and Liviu Matenco. 2016. "Optimal aquifers and reservoirs for CCS and EOR in the Kingdom of Saudi Arabia: An overview." Springerlink. DOI: https://doi. org/10.1007/978-3-319-44726-1_3

Jordan, Dirk C., and Sarah R. Kurtz. 2012. "Photovoltaic Degradation Rates - An Analytical Review." NREL/ JA-5200-51664: 14.

KAPSARC. 2016. "The KAPSARC Energy Model for Saudi Arabia: Documentation of the model build called “KEM-SA_v9.16"." Last accessed Aug. 28, 2018. https:// www.kapsarc.org/wp-content/uploads/2016/11/KEM-SA_ documentation_v9.16.pdf. 
Le Fevre, Chris. "Gas storage in Great Britain." 2013. Oxford Institute for Energy Studies, NG 72: 5. DOI: https://doi.org/10.26889/9781907555657

Matar, Walid and Murad Anwer. 2017. "Jointly reforming the prices of industrial fuels and residential electricity in Saudi Arabia." Energy Policy 109: 747-756. DOI: https:// doi.org/10.1016/j.enpol.2017.07.060

Matar, Walid and Amro M. Elshurafa. 2017. "Striking a balance between profit and carbon dioxide emissions in the Saudi cement industry." International Journal of Greenhouse Gas Control 61: 111-123. DOI: https://doi. org/10.1016/j.ijggc.2017.03.031

Murphy, Frederic, Axel Pierru, and Yves Smeers. 2016. "A Tutorial on Building Policy Models as Mixed-Complementarity Problems." Interfaces 46(6): 465-481. DOI: https://doi.org/10.1287/inte.2016.0842

S\&P Global Platts. 2017. "Saudi Aramco to complete first phase expansion of natural gas network by year end." Accessed May 17, 2018. https://www.platts.com/latestnews/natural-gas/dubai/saudi-aramco-to-complete-firstphase-expansion-26786874.

Saudi Aramco. 2017. "Saudi Aramco annual review 2016." 74.

Saudi Gazette. 2017. "KSA plans to double natural gas production in next 10 years." Accessed Aug. 13, 2018. http://saudigazette.com.sa/article/528440/BUSINESS/ KSA-plans-to-double-natural-gas-production-in-next-10years.
Saudi Geological Survey. "Hydrogeology." 2018. Accessed Aug. 9, 2018. https://www.sgs.org.sa/English/ appliedgeology/pages/hydrogeology.aspx.

Saudi Vision 2030 (SV2030), Government of Saudi Arabia. 2017. "Fiscal Balance Program: Balanced Budget 2020." 38.

Thompson, Matt, Matt Davidson, and Henning Rasmussen. 2009. "Natural gas storage valuation and optimization: A real options application." Naval Research Logistics 56: 226-238. DOI: https://doi.org/10.1002/ nav. 20327

Van den Bergh, Kenneth and Erik Delarue. 2015. "Cycling of conventional power plants: Technical limits and actual costs." Energy Conversion and Management 97: 70-77. DOI: https://doi.org/10.1016/j.enconman.2015.03.026

Wiggins, Seth, and Xiaoli L. Etienne. 2017. "Turbulent times: Uncovering the origins of US natural gas price fluctuations since deregulation." Energy Economics 64: 196-205. DOI: https://doi.org/10.1016/j.eneco.2017.03.015

Yang, Chi-Jen, and Robert B. Jackson. 2011. "Opportunities and barriers to pumped-hydro energy storage in the United States." Renewable and Sustainable Energy Reviews 15: 839-844. DOI: https:// doi.org/10.1016/j.rser.2010.09.020 


\section{Notes}


Notes

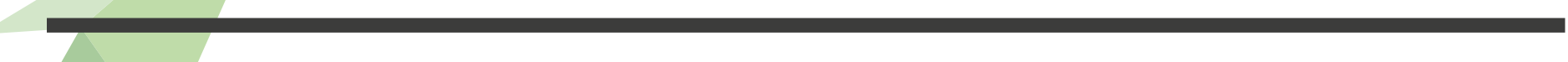




\section{Appendix A Seasonal Natural Gas Storage and Its Usage by Power Plants in KEM}

Natural gas storage is represented by the (linear) equations $A 1$ to A5, below. The set $s$ is defined by summer, a spring and fall seasonal period, and winter. Spring and fall are defined as one 'intermediate' season in the notation. It is important to note that this seasonal set has to be ordered this way as the equations are defined over this specific ordering. The last seasonal period of the year does not automatically link with the seasonal period of the subsequent year. We have to relate the storage operations in the fall of one year to the winter of the following year.

Equation A1 details our seasonal storage approach, where for a given year $(t)$ and region of Saudi Arabia $(r)$, the stored amount $\left(S_{s, t, r}\right)$ in one season is the sum of the stored amount in the previous season and the net amount of injected $\left(I_{s, t, r}\right)$ minus withdrawn gas $\left(W_{s, t, r}\right)$ in the previous season. The amount of injected gas experiences an estimated $1.5 \%$ loss (loss) due to some of the gas being used by the compressor. We use the $0.5 \%$ to $3 \%$ range put forth by Le Fevre (2013). The amounts of injected and withdrawn gas are terms in the constraint that amalgamates the gas demand of each industry and utility in the upstream sector's operation.

Equation A2 is required to join the seasonal periods between years, such that the amount stored in the spring and fall cycles back to inform the storage in the winter of the following year. This equation is written as an inequality to ensure the feasibility in the last annual time segment of the horizon. Since the spring and fall seasons are joined as one seasonal period in KEM, we estimate that half of the period's storage or operation belongs equally to both seasons. The injection and withdrawal variables are then linked to the fuel demand balance.

Although injection and withdrawal rates are non-linear as a function of stored gas relative to the existing storage capacity, representing these relationships mathematically will bring about non-convexity to the model.

Equations $\mathrm{A} 3$ and $\mathrm{A} 4$ ensure built $\left(B_{t, r}\right)$ and existing $\left(E_{t, r}\right)$ storage capacities are balanced throughout the years, and the injection activity does not violate the available storage capacity. Equation A5 imposes a certain quantity of natural gas that cannot be withdrawn to serve as base gas; this is denoted by bmin, which we take as 50\%, based on the EIA (2015).

Investment costs are in the implicit objective function of the upstream sub-model. The capital cost of non-salt storage is estimated at $\$ 6 / \mathrm{MMBtu}$ of working gas, taken from the Federal Energy Regulatory Commission (2004). We assume a life span of 35 years for the storage facility. The fixed operation and maintenance costs are estimated at $1 \%$ of the capital cost (Le Fevre 2013). As we do not have information on the time it takes to construct the storage facility, we estimate a one-year lead time.

\section{Natural gas energy balances throughout the year}

Note: Storage is performed by seasonal period, making sure all seasons in a year are related, and making 
sure all years are related. Moreover, if $s$ is spring and fall, then we divide by two, assuming an equal amount of gas is distributed between the two seasons; this is difficult to show cleanly in Equations A1 and A3.

$\left.S_{s+1, t, r}\right|_{\text {if s=summer }}+\left.S_{s-1, t, r}\right|_{\text {if s=intermediate or winter }}=S_{s, t, r}+(1-$ loss $) I_{s, t, r}-W_{s, t, r}$

$S_{\text {winter }, t+1, r} \leq \frac{S_{\text {intermediate, }, r}+(1-\text { loss }) I_{\text {intermediate }, t, r}-W_{\text {intermediate }, t, r}}{2}$

\section{Natural gas storage capacity constraints}

$$
\begin{aligned}
& E_{t, r}+B_{t, r} \geq S_{s, t, r} \\
& E_{t, r}+B_{t, r} \geq E_{t+1, r} \\
& \left(E_{t, r}+B_{t, r}\right)(1-\text { bmin }) \geq W_{s, t, r}
\end{aligned}
$$

Moreover, the constraints describing the daily transport limit of natural gas to power plants are shown by Equation A6. $U_{p, s, d, t, r}$ are the uses of gas by thermal plant technology $(p)$ in a seasonal period, day type $(d)$, yearly period and region. As we do not have daily granularity in the KEM, this had to be approximated as the average consumption of natural gas by the power utilities in a given season and day type, and could not exceed the daily limit $\left(D C_{t}\right) \cdot N_{s, d}$ are the number of days by seasonal period and day type. $D F_{s, d}$ are the fractions of each type of day in a season. The difference between gas use and withdrawal signifies that the withdrawal in a specific region allows the sector to bypass the daily transport limit.

Although we do not show the dual variables associated with other equations in the appendices, we do it for these equations as their dual variables $\left(\rho_{s, d, t}\right)$ are interpreted as the value reduction of the power system cost by relaxing the gas transport capacity. We show the equations and variables to be orthogonal, as KEM is a mixed complementarity problem.

$0 \leq D C_{t}-\sum_{r} \frac{-W_{s, t, r} D F_{s, d}+\sum_{p} U_{p, s, d, t, r}}{N_{s, d}} \perp \rho_{s, d, t} \geq 0$

The daily transport limit in 2015 and its projections until 2030 were obtained from MEIM. It is worth emphasizing that these are only limits for the power utilities, not for all gas consumers. There is a strong push by local decision-makers to connect power plants to the gas pipeline network. We represent them in the model as they are, and do not allow for further expansion. 


\section{Appendix B Pumped Seawater Storage Hydroelectricity in KEM}

We opted to include seawater hydro storage technology for prospective power generation and/or to be a part of operating reserves. The lower reservoir would be the Red Sea, which for the purpose of our implementation has an infinite amount of water. Some environmental concerns about objects other than saline water making it to the pumping station have made fresh water storage technologies more favorable (Yang and Jackson 2011). The storage plant, if built, could surround the lower reservoir with a net to filter out these objects. Deane et al. (2010) report that 18 years of research and development was needed for corrosion prevention before the first seawater pumped storage plant was built in 1999; Saudi Arabia's construction lead time could be much shorter.

Saudi Arabia is broken up into four operating areas in the model: west, south, central, and east. The central area is landlocked. The eastern area is bounded by the Arabian Gulf, but it does not have any nearby elevation to support PSSH. Therefore, only the western and southern areas can accommodate seawater storage. The Red Sea acts as the lower reservoir, and mountain ranges as close as $1 \mathrm{~km}$ from the coast function as the upper reservoir. Water would be pumped from the sea to the mountains, and then pumped up to a 200-meter elevation to the reservoir. We thus add the dynamic head loss incurred as a result of the $1-\mathrm{km}$ transport, and the 200-m static head, to obtain the total head loss through this process.

The equations and constraints we use to represent PSSH are similar to those of Hale et al. (2016). They balance energy throughout the day by equating the amount stored at any time of the day with stored energy at the previous load segment, the energy input (considering motor and cycle efficiencies), and the energy output. Energy input and output cannot occur simultaneously in the model. The energy stored, corresponding to the volume of water in the upper reservoir, is bounded by upper and lower limits to ensure the storage capacity limit and reliability. We also include equations that ensure generation capacity is not exceeded, and the existing and built capacities are accounted for through time. Following Deane et al. (2010) and Denholm et al. (2013), PSSH plants in our model contribute to the (operating) spinning reserves that serve as a backup to intermittent renewable technologies and to the reserve margin of $100 \%$ of their capacity. 


\section{Appendix C Other Data Input for the Analysis}

This section highlights some of the data used in KEM. Model inputs for power plant life times, ramping costs, capital and operations and maintenance costs are summarized in Table C.1; all costs are denominated in 2015 U.S. dollars (US\$). Figure C.1 displays the assumed capital cost declines for solar and wind turbine technologies. We use a real discount rate of $6 \%$ for power generation and cement manufacturing, whereas an $8 \%$ value is used for the oil and gas upstream, and petrochemicals and fertilizers sectors.

Table C.1. Cost estimates for power generation technologies in 2015.

\begin{tabular}{|c|c|c|c|c|c|}
\hline Power generation technology & $\begin{array}{l}\text { Capital cost } \\
\text { (thousand \$/ } \\
\text { kW) }\end{array}$ & $\begin{array}{l}\text { Fixed O\&M } \\
\text { cost (\$/kW/ } \\
\text { year) }\end{array}$ & $\begin{array}{l}\text { Non-fuel } \\
\text { variable } \\
\text { O\&M cost } \\
\text { (\$/MWh) }\end{array}$ & $\begin{array}{l}\text { Ramping costs } \\
\text { (\$/AMW) }\end{array}$ & $\begin{array}{l}\text { Designed } \\
\text { life time } \\
\text { (years) }\end{array}$ \\
\hline Open-cycle gas turbines (OCGT) & 0.73 & 10.1 & 4.00 & 0.92 & 30 \\
\hline Combined-cycle plants & 0.94 & 19.9 & 3.30 & 0.58 & 35 \\
\hline $\begin{array}{l}\text { Conversion of OCGT to combined-cycle } \\
\text { plants }^{*}\end{array}$ & 0.24 & - & - & - & 20 \\
\hline $\begin{array}{l}\text { Oil- or gas-fired steam turbine (ST) } \\
\text { plants }\end{array}$ & 1.58 & 36.5 & 1.64 & 1.61 & 40 \\
\hline Oil-fired ST plants with SO2 scrubber & 2.03 & 42.0 & 4.43 & 1.61 & 40 \\
\hline Nuclear fission plants & 4.90 & 68.8 & 6.90 & $\begin{array}{l}\text { Not allowed to } \\
\text { ramp }\end{array}$ & 60 \\
\hline PV plants & 0.65 & 26.7 & - & - & 25 \\
\hline $\begin{array}{l}\text { Parabolic trough CSP (with eight hours } \\
\text { of thermal storage) }\end{array}$ & 5.00 & 70.0 & 3.00 & - & 30 \\
\hline Wind turbines (on-shore) & 0.91 & 45.5 & 5.90 & - & 20 \\
\hline PSSH & 0.55 & 18.0 & 0.50 & - & 70 \\
\hline
\end{tabular}

* Conversion has a lower efficiency than new combined-cycle plants and increases capacity of OCGT by 50 percent. Note: O\&M = operations and maintenance.

Sources: KAPSARC analysis; Van den Bergh and Delarue (2015).

The model determines the extent to which thermal plants are utilized. The capacity factors for renewable technologies are determined by the daily resource profiles and any curtailment that may take place. Therefore, the effective capacity factors of renewable plants are endogenous to the model. There is no regulation for the renewable capacity's contribution to the reserve margin. We therefore estimate that PV, CSP with thermal energy storage, and on-shore wind turbines contribute $15 \%, 60 \%$, and $10 \%$ of their existing capacity, respectively, to the planning reserve. We also stipulate an overall reserve margin of $13 \%$ of annual peak loads.

Any existing PV capacity experiences degradation over time. Based on the work of Jordan and Kurtz (2012), we assign a 1\% per year degradation of PV capacity in all but the southern area of the country, due to its unfavorable climate conditions. We estimate any PV capacity built in the south experiences a $0.5 \%$ degradation per year. 
Planned utilization factors that dictate the extent to which plants are taken offline for scheduled maintenance are acquired from ECRA (2010) for each technology. They range from $89 \%$ for steam turbine and combined-cycle plants to $92 \%$ for open-cycle gas turbines. Furthermore, thermal plant heat rate data are estimated from the actual operation of Saudi Electricity Company (SEC) plants in 2015. Thermal plants built after 2015 have values estimated using several sources: 6,093 Btu/kWh for combined-cycle plants, $10,000 \mathrm{Btu} / \mathrm{kWh}$ for OCGT, and 8,804 Btu/kWh for steam turbine plants.

These technologies compete with one another to meet demand at the least cost while satisfying the physical constraints of the power system. The capacity investment plans for power and co-generating plants, in addition to the retirement plans for the power plants are considered; they were obtained from the SEC and the Saline Water Conversion Corporation. Moreover, we impose a $6 \mathrm{GW}$ per year additional upper limit for PV, CSP, and on-shore wind turbines beyond 2023. Past analyses have shown the possibility of bringing substantial quantities of renewable technologies online in the early time periods when fuel prices are made permissible. It was our opinion that supply-side and installation limitations might prevent any sudden and rapid additions of renewable capacity. Regional hourly power loads in 2015 are taken directly from the SEC, and we assume a uniform 5\% per year rise in the exogenous loads across all regions until 2030.

The data inputs for 2015 for cement manufacturing, petrochemical, and fertilizer plants are unchanged from those reported by KAPSARC (2016).

Figure C.1. Capital costs of solar and wind energy technologies in KEM.

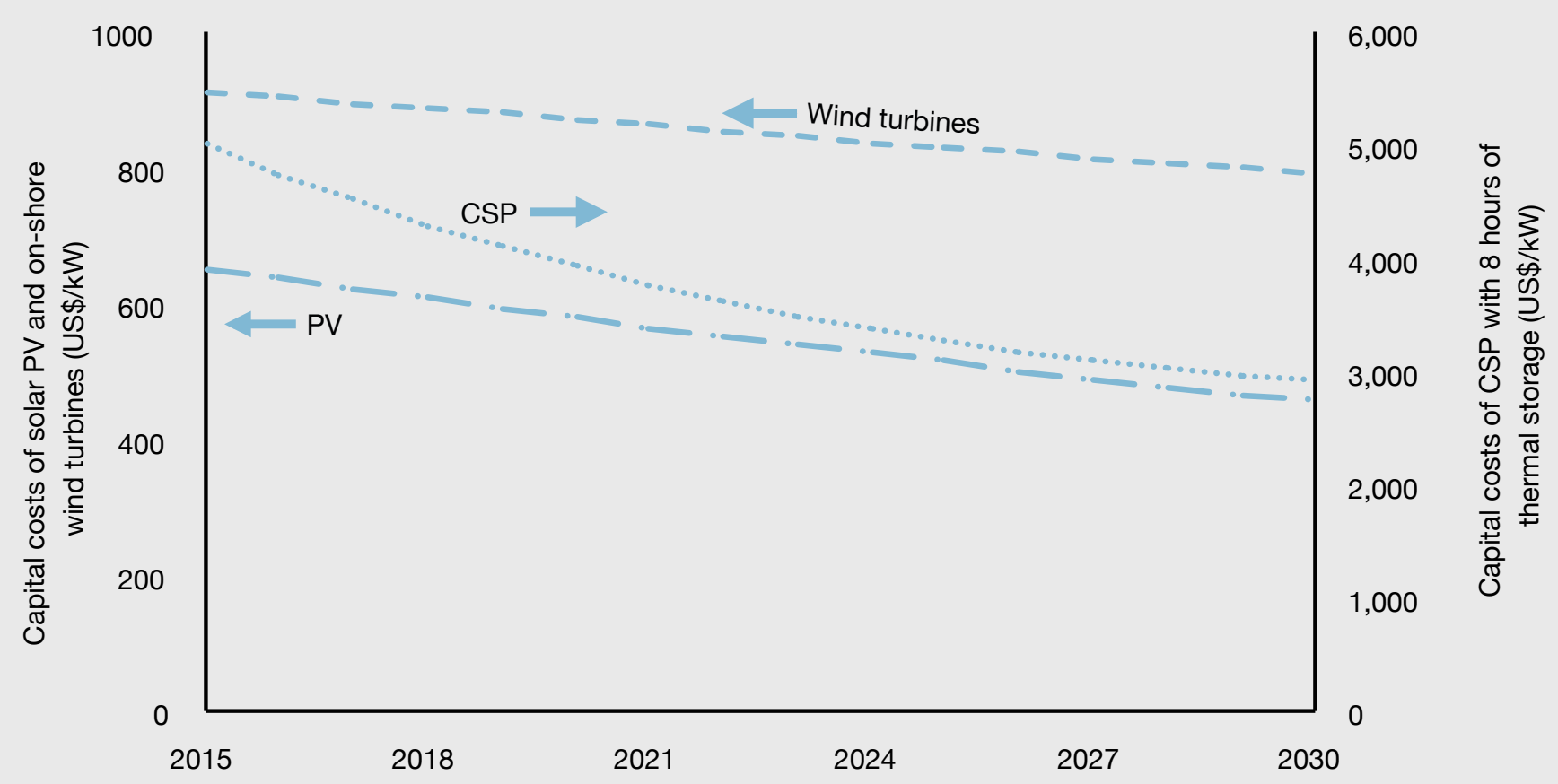

Source: Author estimates. 


\section{About the Authors}

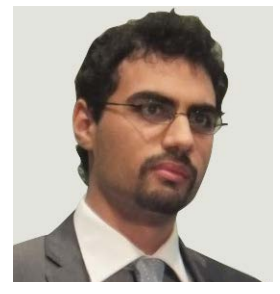

\section{Walid Matar}

Walid is a research fellow at KAPSARC working on energy systems models, particularly the KAPSARC Energy Model, and satellite projects like the residential electricity use model. Walid holds a Master of Science degree in mechanical engineering from North Carolina State University, and a Bachelor of Science degree in the same field from the University of South Carolina.

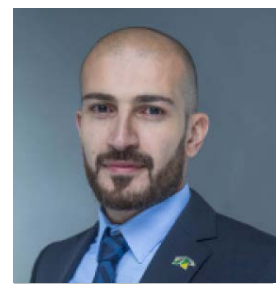

\section{Rami Shabaneh}

Rami is a senior research associate at KAPSARC focusing on global gas and liquids markets. He has more than 10 years of research and industry experience in energy market analysis. He holds an M.S. in Sustainable Energy Development from the University of Calgary.

\section{About the Project}

The study is part of the Future of Natural Gas Markets initiative. It utilizes the KAPSARC Energy Model to understand the impact of natural gas policy on the Saudi energy system. 
INAPSARC

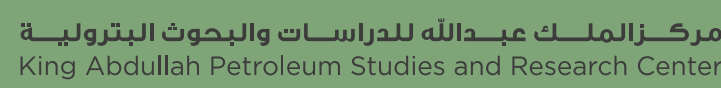

www.kapsarc.org 